BANCA D'ITALIA

E U R O S I S T E M A

Questioni di Economia e Finanza

(Occasional Papers)

International tourism in Italy (1997-2012)

by Andrea Alivernini, Emanuele Breda and Eva lannario 



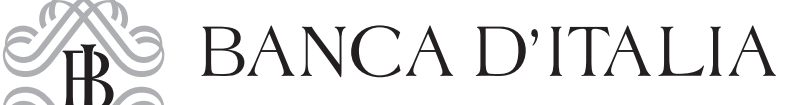

E U ROS I S T E MA

\section{Questioni di Economia e Finanza}

(Occasional papers)

International tourism in Italy (1997-2012)

by Andrea Alivernini, Emanuele Breda and Eva Iannario

Number 220 - July 2014 
The series Occasional Papers presents studies and documents on issues pertaining to the institutional tasks of the Bank of Italy and the Eurosystem. The Occasional Papers appear alongside the Working Papers series which are specifically aimed at providing original contributions to economic research.

The Occasional Papers include studies conducted within the Bank of Italy, sometimes in cooperation with the Eurosystem or other institutions. The views expressed in the studies are those of the authors and do not involve the responsibility of the institutions to which they belong.

The series is available online at www.bancaditalia.it.

ISSN $1972-6627$ (print)

ISSN 1972-6643 (online)

Printed by the Printing and Publishing Division of the Bank of Italy 


\title{
INTERNATIONAL TOURISM IN ITALY (1997-2012)
}

\author{
by Andrea Alivernini ${ }^{\S}$, Emanuele Breda ${ }^{\S}$ and Eva Iannario*
}

\begin{abstract}
The Bank of Italy conducts a sample survey on international tourism at the country's main border crossings for balance-of-payments and analysis purposes. Each year a sample of international travellers (both foreigners in Italy and Italians abroad) who have crossed Italy's borders is interviewed; counting operations are carried out in order to determine the size of the reference population. Between 1997 and 2012 international tourism produced a surplus in Italy's balance of payments. Nonetheless, the tourism balance fell from 1.1 to 0.6 per cent of GDP, mainly due to the fall in real terms of foreigners' expenditure in Italy, whereas expenditure by Italians abroad remained practically unchanged as a share of GDP. As a result, the market share of Italian receipts decreased from 6.8 per cent in 1997 to 3.7 per cent in 2012. During the first years of the recent crisis, Italian international tourism receipts fell at a slower pace than those of its two main European competitors, France and Spain; but in 2011-12 their recovery was faster.
\end{abstract}

JEL Classification: F14, L83.

Keywords: international tourism expenditure, market shares, sample surveys.

\section{Contents}

1. Introduction .5

2. The characteristics of Italy's tourism balance and market shares ..................................6

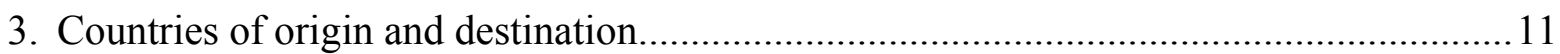

4. Accommodation facilities, reasons for trip, means of transport and travellers' opinions .... 14

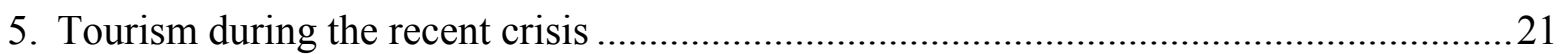

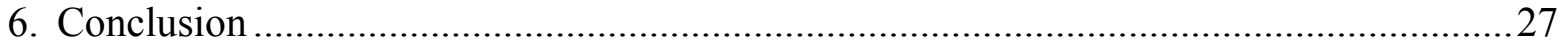

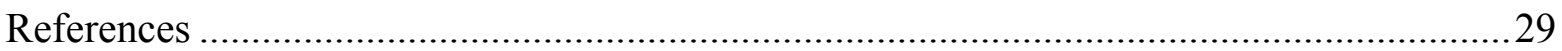

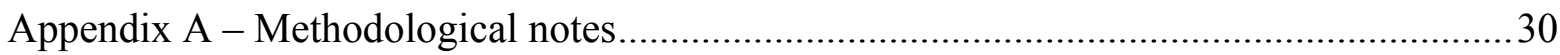

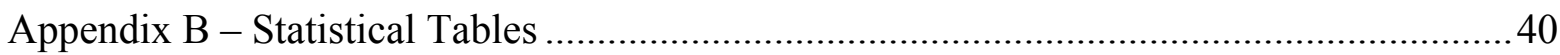

\footnotetext{
$\S$ Banca d'Italia, Statistics Directorate, Via Nazionale 91, 00184 Rome, Italy.

* Banca d'Italia, Statistical Data Collection Directorate, Via Nazionale 91, 00184 Rome, Italy.
} 



\section{Introduction ${ }^{1}$}

In the last two decades tourism has made a positive contribution to global economic growth. While the recent crisis has weakened the expansion of tourist flows as well as of GDP, especially in the advanced countries, it is likely that the positive trend will continue in the medium term and that tourism will go on being a spur to economic growth, above all in the most recently industrialized countries, such as Brazil, Russia, India and China (the BRIC countries). According to the World Tourism Organization (UNWTO), in 2012 international tourist arrivals worldwide increased by 4.1 per cent on $2011,{ }^{2}$ compared with IMF estimates for global GDP growth of 3.0 per cent (and of just 1.3 per cent for the advanced economies). ${ }^{3}$ The growth of this sector has made it important both in terms of directly generated value added and with respect to the demand activated in related services sectors (such as trade and transport) and in the production of goods and services consumed by tourists. The data collected by the OECD (2012), show that in 2010 tourism accounted directly for 4.2 per cent of GDP in the OECD countries and for 5.5 per cent in the EU countries. Among the main European countries, receipts from foreign tourism in 2012 exceeded 3 per cent of GDP in Austria, Spain and Turkey; while expenditure abroad exceeded 2 per cent in Austria, Germany and the United Kingdom (Figure 1). Outside Europe, tourism consumption was particularly high in Mexico and New Zealand. The Italian Tourism Satellite Account (TSA) shows that in 2010 the value added by activities connected to tourism accounted for 6 per cent of total Italian value added (see Istat et al., 2012). According to previous estimates (see Alivernini, 2012), the ratio of domestic and international tourism expenditure to GDP in 2008 was about 5 per cent. $^{4}$

This report is organised as follows. Chapter 2 presents the trends of the items in the tourism balance of payments from 1997 to 2012 and of Italy's market share. Chapter 3 presents the expenditure in the countries of origin and destination. Chapter 4 describes the accommodation facilities used, reasons for travel, and visitors' opinions. The report concludes with an in-depth analysis of trends in tourism receipts and expenditure in Italy during the recent economic and financial crisis. Finally, Appendix A describes the methodology of the survey on international tourism and Appendix B presents some additional tables.

1 We are grateful for their helpful comments to Enrico Beretta, Luigi Cannari, Giovanni D’Alessio, Silvia Fabiani, Roberto Tedeschi and the participants at the seminar "The trends of Italy's international tourism” held at the Bank of Italy in June 2012. This paper is the updated English version of Alivernini et al. (2013a). Any errors are the authors' alone; the opinions expressed are personal views and do not necessarily reflect those of the Bank of Italy.

2 UNWTO (2013).

3 IMF (2014).

4 This estimate is not entirely comparable with that of the TSA, mainly because it excludes expenditure on international transport, which according to the compilation rules of the balance of payments is not included under tourism expenditure. This component accounted for around 0.7 per cent of GDP in 2008. 
Figure 1

\section{International travel flows in selected OECD countries in 2012}

(current values as a share of GDP)

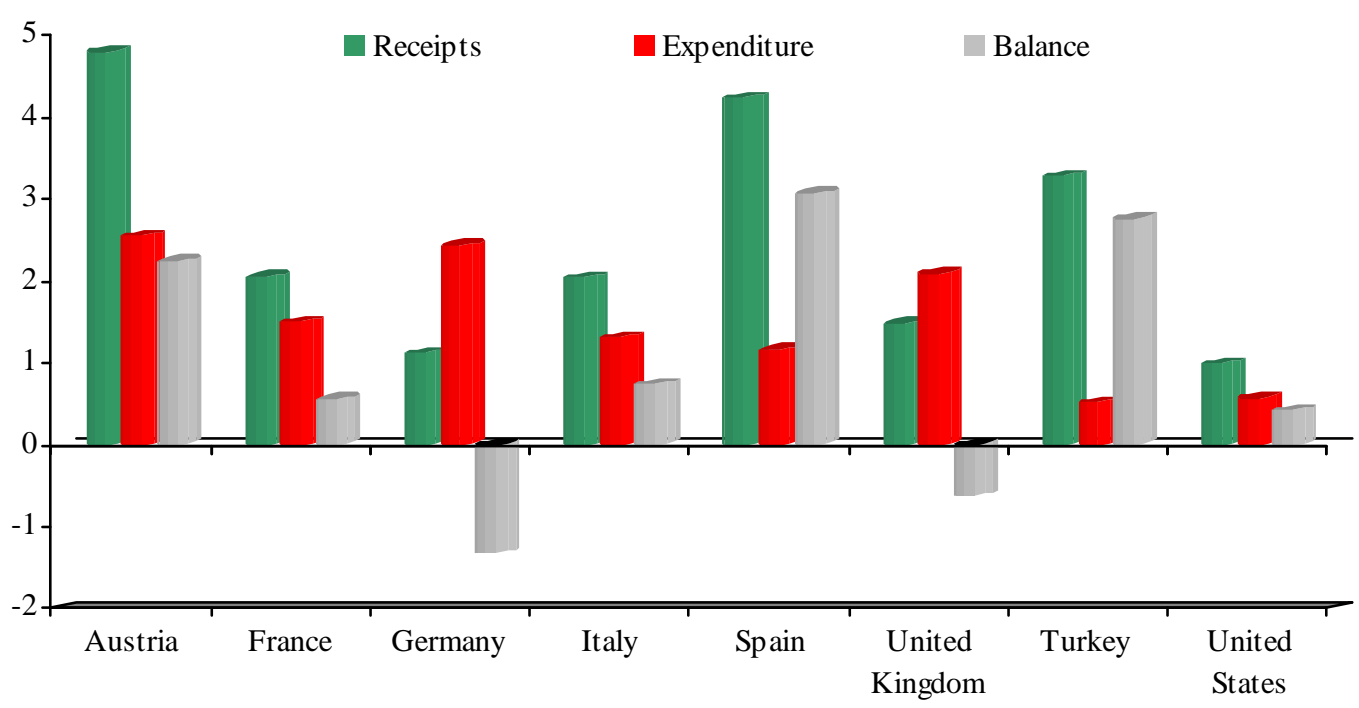

Source: based on Eurostat data.

\section{The characteristics of Italy's tourism balance and market shares}

\subsection{International flows and the tourism balance}

Between 1997 and 2012 foreigners' expenditure in Italy (which is recorded as exports in the balance of payments) fell in real terms by an average 0.9 per cent a year. ${ }^{5}$ As a share of GDP, whose real growth in the same period was modest (averaging 0.5 per cent a year), it declined from 2.5 to 2.0 per cent. In the same period expenditure by Italians abroad at constant prices (imports) expanded at a yearly average rate of 0.2 per cent, remaining practically unchanged as a share of GDP (declining from 1.4 per cent in 1997 to 1.3 per cent in 2012). International tourism's contribution to the growth of Italy's GDP was therefore negative in the last sixteen years.

5 Since there is no index of the prices of tourist goods and services and considering that tourists purchase a broad range of goods and services in the places they visit, for receipts the deflator of expenditure in Italy by nonresidents was used, and for expenditure the deflator of spending abroad by Italian residents, both drawn from the Istat National Accounts. 


\section{Balances of services and international travel in Italy}

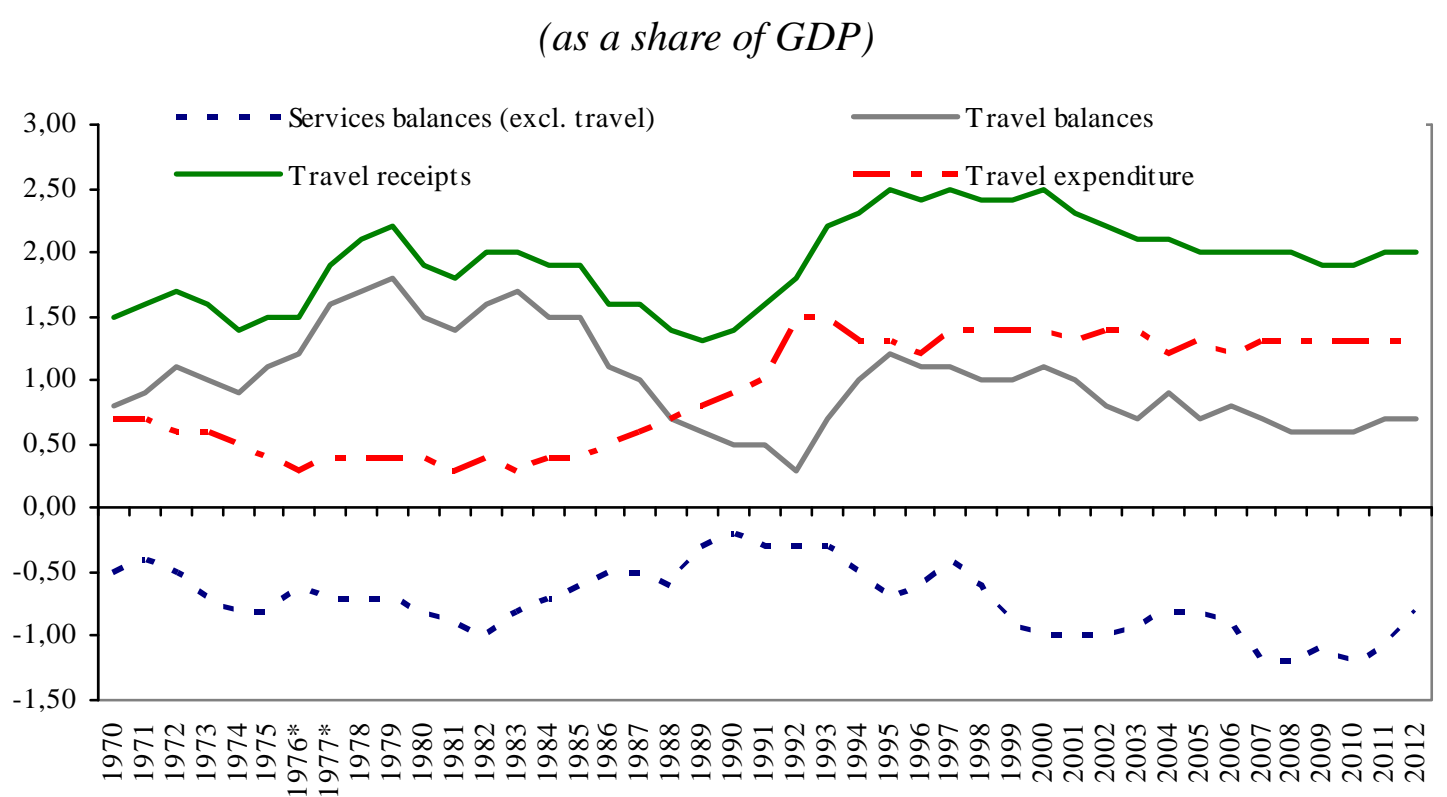

Sources: based on Bank of Italy and Istat data.

(*) Interruptions in the travel data series: in 1976 for expenditure, in 1977 for receipts.

Between 1997 and 2012 Italy's current account balance went from a surplus of 2.8 per cent of GDP (at current prices) to a deficit of 0.4 per cent. The main negative contribution came from goods, whose balance deteriorated by 2.2 percentage points of GDP. This was primarily due to the end of the effects of the lira devaluations of the early 1990s, to the cyclical slowdown produced by the public finance adjustment measures of 1992-95 and, in the last decade, to the increase in the prices of imported energy products. International trade in services contributed 0.7 percentage points of GDP to the worsening of the current account balance, of which 0.4 points are attributable to international travel and 0.3 points to transport and other services. ${ }^{6}$ The deterioration of the tourism balance, the only item in Italy's current account that consistently showed a surplus, dates back to the 1980s, ${ }^{7}$ with an interruption in the mid-1990s due to the temporary gains in competitiveness generated by the lira devaluations of 1992 and 1995 and the cyclical weakening in domestic demand (which affected expenditure abroad by Italian travellers). Between 1997 and 2010 the tourism balance in Italy fell from 1.1 per cent of GDP to a minimum of 0.6 per cent (Figure 2 and Table 1). In 2011 and 2012, after the surplus as a share of GDP had declined for four consecutive years, the tourism balance made a slight recovery (to 0.7 per cent of GDP), above all owing to the acceleration in expenditure by foreign tourists. ${ }^{8}$

6 Which in turn are subdivided into financial, insurance, computer, government, personal and communication services, construction, royalties, and “other business services".

7 While data from the survey on international tourism are available from 1997, the time series of travel receipts, expenditure and balance vis-à-vis the rest of the world goes back to 1970 (data were mainly obtained from banks statistics related to the exchange of foreign currency).

8 See Section 3.1. 


\section{Tourism balance of payments}

(billion euros)

\begin{tabular}{|c|c|c|c|c|c|c|c|c|c|c|c|c|c|c|c|c|}
\hline & 1997 & 1998 & 1999 & 2000 & 2001 & 2002 & 2003 & 2004 & 2005 & 2006 & 2007 & 2008 & 2009 & 2010 & 2011 & 2012 \\
\hline & \multicolumn{16}{|c|}{ Current prices } \\
\hline Receipts & 26.3 & 26.8 & 26.7 & 29.9 & 29.0 & 28.2 & 27.6 & 28.7 & 28.5 & 30.4 & 31.1 & 31.1 & 28.9 & 29.3 & 30.9 & 32.1 \\
\hline Expenditure & 14.7 & 15.8 & 15.9 & 17.0 & 16.6 & 17.8 & 18.2 & 16.5 & 18.0 & 18.4 & 20.0 & 20.9 & 20.0 & 20.4 & 20.6 & 20.5 \\
\hline \multirow[t]{2}{*}{ Balance } & 11.6 & 11.0 & 10.9 & 12.9 & 12.4 & 10.4 & 9.4 & 12.2 & 10.5 & 12.0 & 11.2 & 10.2 & 8.8 & 8.8 & 10.3 & 11.5 \\
\hline & \multicolumn{16}{|c|}{2005 Prices } \\
\hline Receipts & 31.5 & 31.5 & 30.9 & 33.7 & 31.8 & 30.2 & 28.8 & 29.2 & 28.5 & 29.7 & 29.9 & 28.9 & 26.6 & 26.6 & 27.3 & 27.5 \\
\hline Expenditure & 16.8 & 18.1 & 17.7 & 17.4 & 16.6 & 17.9 & 19.1 & 17.3 & 18.0 & 17.9 & 19.3 & 20.0 & 19.2 & 18.4 & 18.0 & 17.3 \\
\hline Balance & 14.7 & 13.4 & 13.2 & 16.4 & 15.2 & 12.3 & 9.6 & 11.9 & 10.5 & 11.9 & 10.6 & 9.0 & 7.5 & 8.2 & 9.3 & 10.2 \\
\hline
\end{tabular}

Between 1997 and 2012 the limited growth in receipts came about in an international context characterized by a decline in the average number of days per trip, an increase in the supply of tourist destinations inside and outside Europe and, above all in the last decade, the expansion of low-cost airlines. These operators enable travellers to reach mid-distance destinations at a moderate cost, favouring, amongst other things, more international weekend travel (short breaks). For Italy, the effects on total expenditure owing to the tendency to shorten trip durations were not fully offset by the modest increases in average daily expenditure at current prices and the number of arrivals in the country (which between 1997 and 2012 expanded at an average annualized rate of 1.7 per cent). Along with the resilience of expenditure abroad by Italians as a share of GDP, this development led to a fall in the tourist surplus as a share of output.

Following the peaks of 5.5 days in 2000 and 2004, the average length of trips by foreigners to Italy declined rapidly to 4.3 days in 2012 (Table B.1); that of Italians increased to 5.2 days in 2004, before falling to 4.4 days in 2012.

At current prices, daily per capita expenditure by foreigners in Italy declined from $€ 86$ to $€ 80$ between 1997 and 2002, but made a significant recovery in the period that followed (rising to $€ 98$ in 2012). ${ }^{9}$ Per capita daily expenditure abroad by Italians was consistently lower than that of foreigners.

Day trippers, whose expenditure amounted in 2012 just to 8 per cent of total tourism expenditure for Italians and some 5 per cent for foreigners, make up a significant proportion of travellers (in 2012 they accounted for more than 50 per cent of Italians and almost 40 per cent of foreigners; Table B.2).

Day trippers are a sub-population found almost exclusively in the northern regions of Italy, and their overall economic impact is barely significant. They are excluded from several of the analyses in this report, including of course those which examine the accommodation facilities used.

9 At 2005 prices, the average daily expenditure of foreigners in Italy fell from over $€ 100$ in 1997 to $€ 84$ in 2012 ; in the same period, the average daily expenditure of Italians, again at 2005 prices, fell from $€ 79$ to $€ 67$. 


\subsection{The market shares of Italy and the main economies}

In $1982^{10}$ Italy received 7.9 per cent of world tourism receipts and ranked second in the world by market share. In less than thirty years this figure more than halved, reaching 3.7 per cent in 2012 (Figures 3a-3b). In the same period its two main competitors, France and Spain, experienced less severe reductions (France's share of world tourism receipts fell from 6.9 to 4.8 per cent; Spain's from 7.0 to 5.0 per cent). ${ }^{11}$

The United States holds the world's largest market share of receipts from international travel. From 1982 to 2012, ${ }^{12}$ while maintaining its position as front runner, this share oscillated between a low of 13.7 per cent and a high of 21.0 per cent; in the last ten years the United States' market share was especially penalized by the restrictions on the granting of entry visas to foreign visitors introduced following the terrorist attacks of 11 September 2001.

The decline in the market shares of the countries whose tourism tradition stretches back furthest (in addition to the four countries just mentioned, Austria and the United Kingdom, each of which accounted for 5.5 per cent of world receipts in 1982) was also an effect of the development of tourism in emerging nations such as Turkey and China.

China opened up to international travel in the second half of the 1990s after a long period in which there were tight border restrictions, while Turkey and other countries that have recently entered the international tourism market have exploited the tourist potential of their countries to great effect. Destinations that once appeared too costly or difficult to reach, for example tropical countries, have focused on tourism as a factor for the development of their economies through the creation of dedicated infrastructures and greater attention to foreign visitors. These countries have eroded the market shares of the more "traditional" destinations, such as the countries of the Mediterranean area, and especially of seaside destinations.

World Trade Organization data on tourism market shares are available for all the main countries of destination as of 1982.

11 In Spain, the relatively stronger performance of receipts compared with Italy, as well as the making up of lost ground by the Iberian economy in the 1980s, appears to have been determined by factors other than price competitiveness (such as the quality of services, infrastructure, transport etc.), which in the last decade has deteriorated with respect to Italy in terms of both the real effective exchange rate and consumer prices.

12 In these years data on international travel receipts produced by the World Trade Organization (WTO) are available for all the main countries. These data were preferred to those of the United Nations World Tourism Organization (UNWTO), commonly used in international comparisons of tourism economics, for the sole reason that for the United States the WTO employs a definition of receipts consistent with the fifth edition of the IMF's Balance of Payments Manual and with the definition adopted in the other countries, which includes the expenditure of foreign citizens on study trips (see IMF, 1993). 
Figure 3a

Market shares of receipts from international travel: Italy and the main EU countries (per cent; data at current prices and exchange rates)

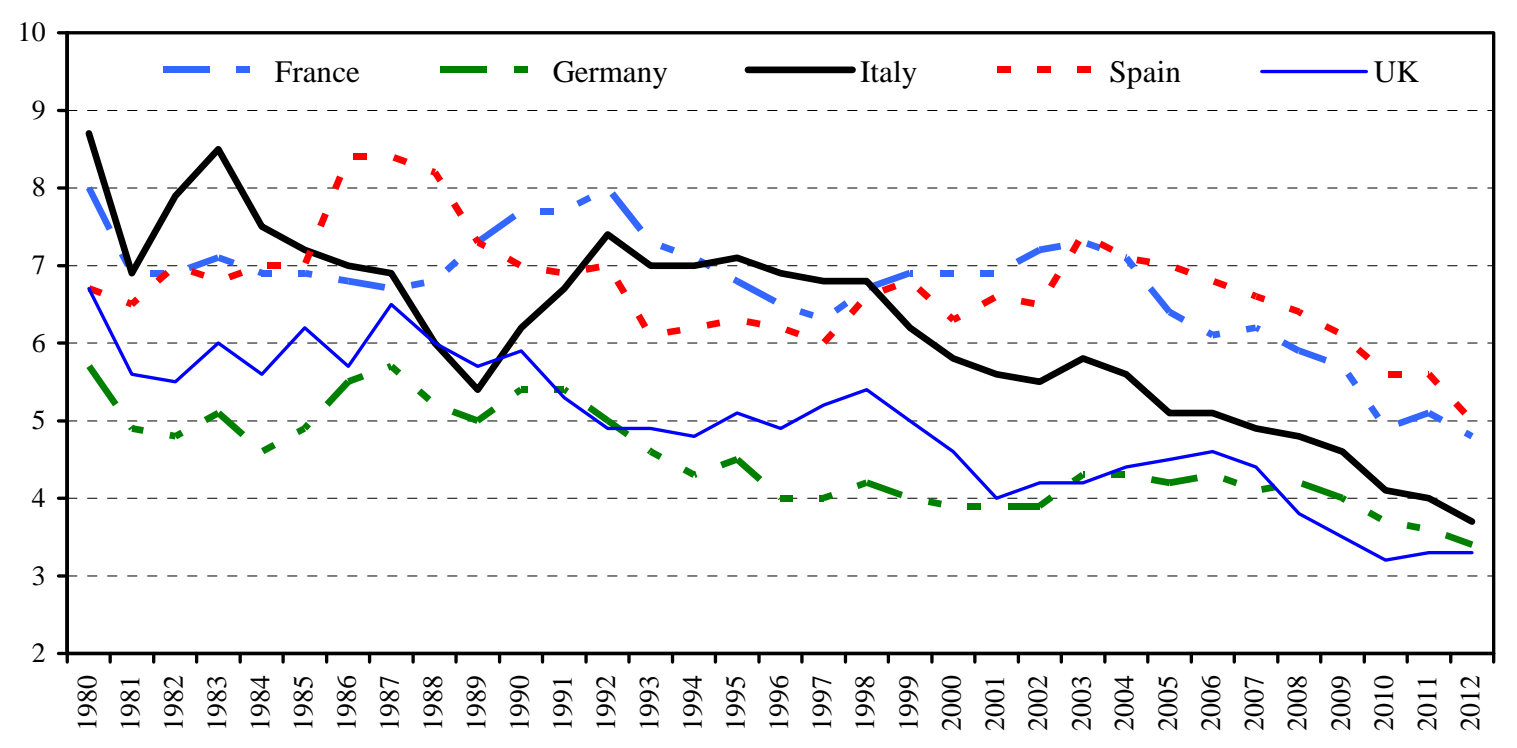

Source: based on World Trade Organization (WTO) data.

Figure 3b

Market shares of receipts from international travel: Italy and non-EU countries (per cent; data at current prices and exchange rates)

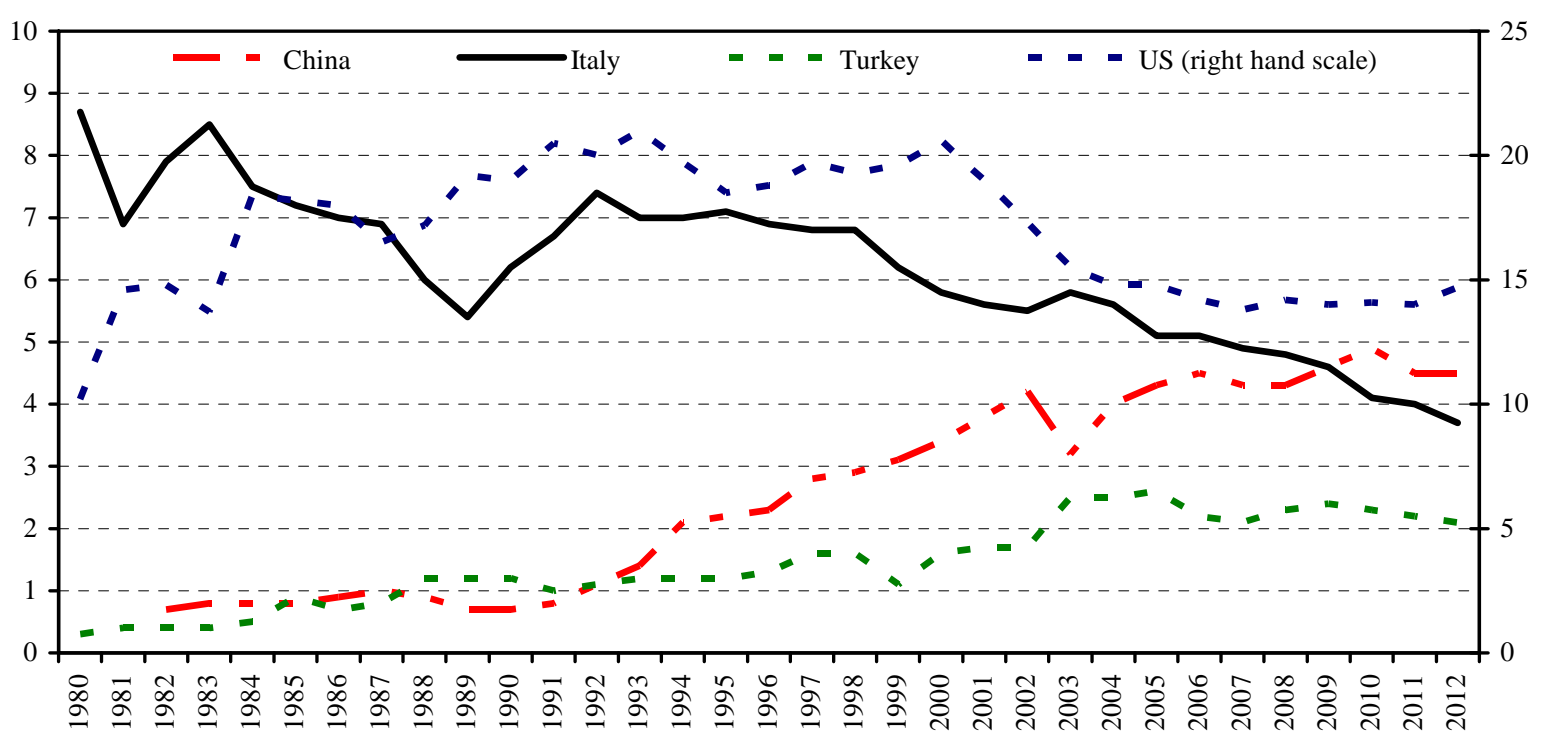

Source: based on World Trade Organization (WTO) data. 


\section{Countries of origin and destination}

\subsection{Foreign tourists' countries of origin}

Tourism revenues in Italy mainly come from nearby countries, whose residents have the advantage of less distance to travel and, in the case of states which are part of the European Monetary Union, a common currency.

Traditionally, Germany is the main market for Italy's international tourism. It is, after all, the European country with the largest population, with over 80 million inhabitants, a high standard of living and a long tradition of travels in Italy. Nevertheless, since the early 2000s, spending by German tourists has been declining. In 1997, Germans spent almost €6.5 billion in Italy (about a quarter of Italy's total tourism revenues); spending declined to almost $€ 4.5$ billion in the years 2009 and 2010, less than one sixth of total revenues, then in 2011 and 2012 it grew to $€ 5.1$ billion and $€ 5.3$ billion, respectively. The average stay of German tourists fell from 8.2 to 6.1 days (Table 2). The reduction in spending was especially pronounced in the North-East, traditionally a popular destination for German visitors, who now prefer other Mediterranean countries, in particular Croatia, for their beach holidays.

The United States is the second country of origin in terms of tourism revenues for Italy, with about €3.6 billion spent in 2012 (11 per cent of the total). Revenues from the United States were adversely affected in 2002 and 2003 by the terrorist attacks of 11 September 2001, which temporarily discouraged US citizens from travelling abroad; tourist earnings then began to increase again and peaked in 2006 at over $€ 3.84$ billion (12 per cent of the total). US spending fell again by 17 per cent in 2008, reflecting the economic crisis, and then increased by 7.7 per cent in 2012, with a per capita average of $€ 128$ per day and an average stay of 10.8 days. However, average spending and average length of stay both fell compared with 1997 (€135 and 11.9 days).

Table 2

\section{Spending at current prices, number of tourists and length of stay by country of origin}

1997-2012

\begin{tabular}{|c|c|c|c|c|c|c|c|}
\hline & \multirow{2}{*}{$\begin{array}{c}\text { Average annual } \\
\text { percentage } \\
\text { change in } \\
\text { spending (\%) }\end{array}$} & \multicolumn{2}{|c|}{$\begin{array}{l}\text { Per capita daily } \\
\text { spending (euros at } \\
\text { current prices) }\end{array}$} & \multicolumn{2}{|c|}{$\begin{array}{l}\text { Number of tourists } \\
\text { (thousands) }\end{array}$} & \multicolumn{2}{|c|}{$\begin{array}{c}\text { Average length of stay }{ }^{1} \\
\text { (days) }\end{array}$} \\
\hline & & 1997 & 2012 & 1997 & 2012 & 1997 & 2012 \\
\hline Germany & -1.2 & 58.0 & 85.5 & 15,818 & 11,713 & 8.2 & 6.1 \\
\hline United States & 1.4 & 135.4 & 128.1 & 1,816 & 3,076 & 12.3 & 10.8 \\
\hline France & 3.3 & 64.0 & 90.1 & 9,370 & 10,260 & 6.8 & 6.4 \\
\hline United Kingdom & 3.2 & 96.3 & 104.1 & 1,840 & 3,660 & 9.1 & 6.9 \\
\hline Switzerland & 2.3 & 85.8 & 143.4 & 9,456 & 13,166 & 6.7 & 4.5 \\
\hline Austria & 0.1 & 78.1 & 103.9 & 6,557 & 6,949 & 5.8 & 4.5 \\
\hline Spain & 6.2 & 78.5 & 74.8 & 925 & 2,638 & 7.7 & 7.3 \\
\hline Russia & 3.1 & 225.2 & 150.4 & 256 & 1,050 & 13.0 & 8.3 \\
\hline Netherlands & 5.2 & 65.7 & 81.5 & 946 & 1,927 & 8.9 & 7.5 \\
\hline Other European countries & -0.7 & 152.1 & 106.9 & 3,439 & 4,641 & 11.4 & 12.4 \\
\hline Other non-European countries & 3.6 & 79.8 & 83.6 & 9,454 & 17,655 & 11.0 & 6.7 \\
\hline Total & 1.3 & 85.6 & 97.8 & 59,878 & 76,734 & 8.6 & 7.0 \\
\hline
\end{tabular}


France is the third most important origin of Italy's incoming tourists. In 2012 French tourists spent $€ 2.9$ billion in Italy (9.0 per cent of total revenues), a 1.7 per cent increase on 2011, lower than the yearly average increase of the period 1997-2012 (3.3 per cent). The average daily amount spent by French tourists was one of the highest among the euro-area countries (€90). Their average length of stay, considering only overnight stays, was 6.4 days.

In 2012 the citizens of the United Kingdom and Switzerland spent more than $€ 2$ billion in Italy, with an average annual increase between 1997 and 2012 of 3.2 and 2.3 per cent respectively. During the period under consideration, there was a sharp contraction in the average length of stay for both countries. Switzerland also recorded an increase in daily per capita spending, whereas UK daily expenditure in Italy stagnated. Almost three quarters of Swiss tourists do not stay overnight in Italy: excluding them, the average stay rises to 4.5 days.

Austria, Spain and the Netherlands accounted for between 3.3 and 4.6 per cent of Italy's revenues in 2012. Spending by Austrians remained basically unchanged between 1997 and 2012, while tourists from Spain and the Netherlands increased their spending significantly. The countries that joined the EU during the last decade increased their spending on tourism in Italy considerably in the period 1997-2012,: from just over €600 million in 1997 (2.3 per cent of total tourism revenues in Italy) to $€ 2.4$ billion (7.5 per cent of the total), with an average annual increase of about 10 per cent. In particular, spending by tourists from Romania and the Czech Republic increased on average by 18 and 12 per cent, respectively, each year. Data on new EU member countries suggest that their admission encouraged tourist flows to Italy, thanks to the abolition of border restrictions; greater economic and social integration; and the increase in migration flows from some of these countries towards Italy (in particular from Romania), which led to an increase in non-residents coming to visit workers who had settled in Italy.

Spending by Japanese tourists in Italy declined sharply and continuously. In 1997 these tourists spent almost €2.5 billion and in 2012 about $€ 600$ million, a drop in spending and in number of visitors of 77 per cent. The share of spending by Japanese tourists in Italy fell from 9.4 per cent to less than 2 per cent of total incoming revenues. Japan's longstanding economic stagnation has had a significant effect on its inhabitants' propensity to travel. The outgoing spending of Japanese tourists in 2000 accounted for 6.7 per cent of the world total; in 2012 this figure had fallen to 2.6 per cent. However, the Japanese have maintained high average per capita daily spending, probably in line with their per capita incomes.

Chinese tourists do not visit Italy in large numbers despite their country's impetuous economic development and the reduction of the barriers to foreign tourism imposed by their authorities. They spent only about $€ 300$ million in 2012 ( 1 per cent of total revenues) although this was a 29 per cent increase on 2011 (and almost 60 per cent more than in 2010). As receipts from China amounted to $€ 140$ million in 1997, the average yearly increase from 1997 to 2012 was 5.8 per cent.

In general, with the partial exception of Russia and despite the large increase in Chinese tourists in 2011-12, revenues from the BRIC countries are still generally low (7.2 per cent of the total in 2012). In terms of size and rate of GDP growth these countries are the most important new markets, including for tourism. This poor result indicates the need for better coordinated and more effective policies to promote tourism. This is particularly important in the case of these markets, which are geographically and culturally distant.

Between 1997 and 2012 tourist spending flows by continent of origin saw a drop in the share of revenues coming from Asia (from 13 per cent to 7 per cent), largely due to the fall in 
spending by Japanese residents, which was not fully offset by the spending of the other Asian countries. The corresponding increase in the share of EU countries (from 54 per cent to 59 per cent; Figure 4) can be explained by the 12 new countries that joined the EU and the greater spending by tourists from the older members of the EU, excluding Germany. Nevertheless, between 1997 and 2012, the loss of share in the Italian market of non-EU countries was limited (despite some of these countries leaving the group to become part of the EU), thanks above all to the increase in spending by the Swiss (an annual average of 2.3 per cent) and by the Russians (3.1 per cent).

Figure 4

\section{Foreigners' spending by continent of residence, 1997 and 2012}

(per cent)
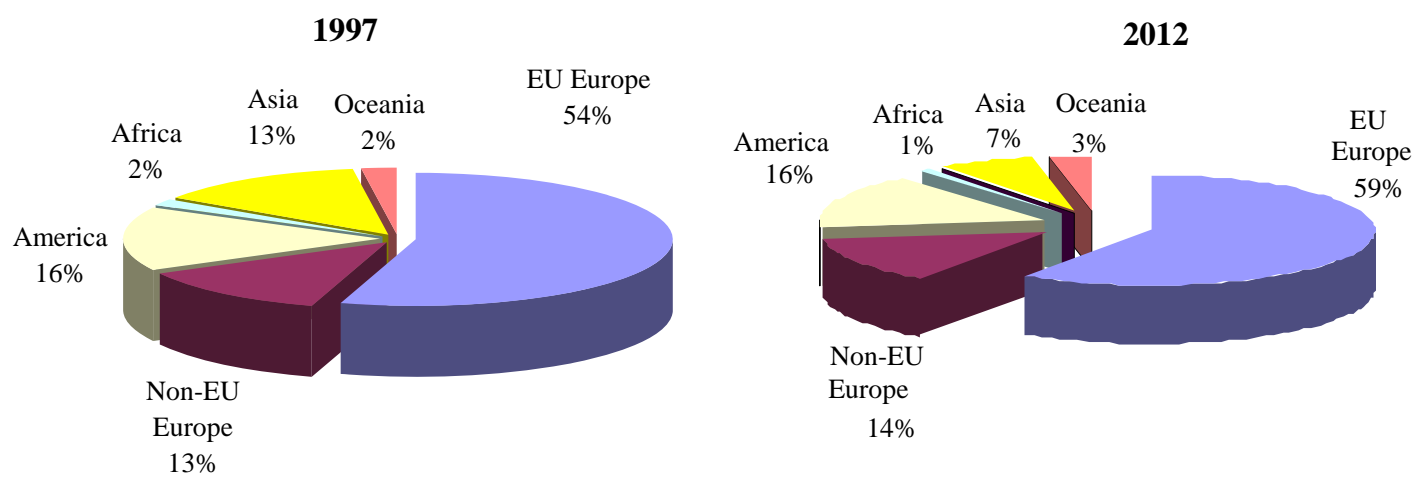

\subsection{Italian tourists' destinations abroad}

When travelling abroad, Italians favour France. Its proximity to Italy and its tourist destinations and traditions put it in first place in terms of spending (10 per cent of Italians' total spending abroad in 2012), for the number of tourists staying overnight, ${ }^{13}$ and the overall number of overnight stays (Table B.4). Over the last 16 years, spending in France has overtaken that in the United States (the second country in terms of Italian tourists' spending abroad in 2012). In 1997, spending by Italian tourists in the United States was almost one tenth more than in 2012. The change occurred at the start of the last decade, probably as a result of US entry restrictions after the events of 2001, which provoked a generalized reduction in the number of international tourists visiting the United States. After France and the United States, Spain ranks third and has more than doubled its revenues from Italy in the period under consideration, with the share of total tourist spending by Italians equal to 7.8 per cent in 2012, although in the last year Italians' expenditure in Spain dropped by 11 per cent.

Spending in Switzerland, Germany and the United Kingdom accounts for more than 6 per cent of the total in each of these countries, in which business travel produces large flows. In the case of Switzerland there are large flows of cross-border workers.

In the period 1997-2012 the share of Italy's total spending increased for Greece, Austria, the Netherlands, Slovenia and, in particular, China and Romania. As regards the latter, part of the increase reflects the effect of Romanian immigrants now settled in Italy returning for home

13 As regards number of tourists, France is second to Switzerland but 90 per cent of the Italians who visit Switzerland are only making day trips. 
visits. ${ }^{14}$ Spending by Italians in Egypt grew sharply until 2010, particularly in the beach holiday sector. In 2011, as a result of the troubles in the country and in North Africa in general, spending almost halved compared with 2010; in 2012 it was at the level recorded in 2005. This was also the case for Morocco where spending by Italians increased sharply until 2008, when it accounted for 2.1 per cent of the total, followed by a decisive downward trend (in 2012 the share fell to 0.9 per cent). In real terms, spending by Italians increased by an annual 1.1 per cent overall for European destinations and fell by 1.1 per cent for non-European destinations.

\section{Accommodation facilities, reasons for trip, means of transport and travellers' opinions}

\subsection{Use of accommodation facilities}

Hotels/holiday villages (hereinafter: hotels) ${ }^{15}$ are traditionally the type of accommodation most commonly used by tourists. Some 37 per cent of foreign tourists' overnight stays in Italy in 2012 were in hotels (Table 3); private accommodation (holiday rentals, staying with relatives or friends, second homes) accounted for 44 per cent and other types of accommodation operated as enterprises (campsites, bed and breakfasts and holiday farms) for less than 10 per cent.

Table 3

\section{Breakdown of foreign visitors' overnight stays by type of accommodation, 1997-2012}

(per cent; totals in millions of overnight stays)

\begin{tabular}{|c|c|c|c|c|c|c|c|c|c|c|c|c|c|c|c|c|}
\hline & 1997 & 1998 & 1999 & 2000 & 2001 & 2002 & 2003 & 2004 & 2005 & 2006 & 2007 & 2008 & 2009 & 2010 & 2011 & 2012 \\
\hline Hotel & 40.2 & 39.8 & 39.1 & 38.6 & 38.4 & 34.8 & 34.3 & 35.0 & 33.5 & 35.4 & 35.8 & 35.1 & 34.9 & 35.8 & 37.5 & 37.4 \\
\hline Holiday rental & 17.7 & 18.4 & 19.9 & 20.8 & 21.6 & 23.0 & 23.3 & 22.3 & 21.5 & 20.1 & 20.8 & 19.8 & 18.1 & 17.8 & 18.3 & 18.2 \\
\hline $\begin{array}{l}\text { Staying with relatives or } \\
\text { friends }\end{array}$ & 19.8 & 19.1 & 18.5 & 17.1 & 17.9 & 18.5 & 19.1 & 19.5 & 20.9 & 21.6 & 20.4 & 21.4 & 22.9 & 21.9 & 20.4 & 20.5 \\
\hline Own home & 9.3 & 7.5 & 7.5 & 7.6 & 7.6 & 8.5 & 9.4 & 10.3 & 8.6 & 9.0 & 8.1 & 7.0 & 6.3 & 6.3 & 5.3 & 4.9 \\
\hline Campsite & 5.5 & 6.4 & 6.7 & 6.8 & 6.7 & 8.0 & 7.7 & 6.1 & 6.6 & 4.9 & 5.1 & 6.0 & 6.1 & 5.4 & 5.3 & 5.1 \\
\hline Holiday farm ${ }^{(1)}$ & - & - & - & - & - & - & - & - & 1.3 & 1.2 & 1.7 & 1.1 & 1.2 & 1.1 & 1.1 & 0.9 \\
\hline Bed \& breakfast ${ }^{(2)}$ & - & - & - & - & - & - & - & - & - & - & - & 1.9 & 2.5 & 3.0 & 2.8 & 3.3 \\
\hline Other ${ }^{(3)}$ & 7.6 & 8.8 & 8.3 & 9.1 & 7.8 & 7.3 & 6.2 & 6.9 & 7.6 & 7.7 & 8.1 & 7.7 & 8.1 & 8.7 & 9.3 & 9.6 \\
\hline $\begin{array}{l}\text { Total (millions of } \\
\text { overnight stays) }\end{array}$ & 307 & 306 & 331 & 356 & 341 & 352 & 341 & 325 & 327 & 349 & 351 & 332 & 314 & 312 & 327 & 328 \\
\hline
\end{tabular}

(1) Recorded separately from February 2005 onwards; previously included in "holiday rental”.

(2) Recorded separately from April 2008 onwards; previously included in "holiday rental".

(3) Includes: motor caravans/campers, cruise ships, youth hostels, residential institutions, clinics, other

In the period 1997-2003 the share of overnight stays in private facilities increased, eroding that of hotels; hotels subsequently regained ground, with a particularly marked recovery in

14 According to the balance of payments concepts and definitions, residents in a given country are the individuals who maintain the centre of their personal economic interests there for more than one year. Thus, immigrants who have lived in Italy for more than one year and return to their country of origin to visit their families are considered as residents in Italy for the purposes of the balance of payments even if they hold a foreign passport.

15 In the questionnaire, holiday villages are grouped with hotels because interviewees are not always able to distinguish between the two. 
2010. ${ }^{16}$ The most recent types of accommodation - holiday farms and bed and breakfasts - are relatively less important, with between 1 and 3 per cent of foreigners' total overnight stays.

The share of overnight stays in hotels by Italians abroad recorded a decrease, from 38.2 per cent in 1997 to 36.5 per cent in 2012, together with the share of holiday rentals, which slipped from 25.8 to 23.2 per cent, and campsites; the shares of overnight stays in accommodation provided by relatives and friends or in a home that tourists owned grew (Figure 5).

Figure 5

\section{Overnight stays of Italians abroad by type of accommodation, 1997-2012}

(percentage share)

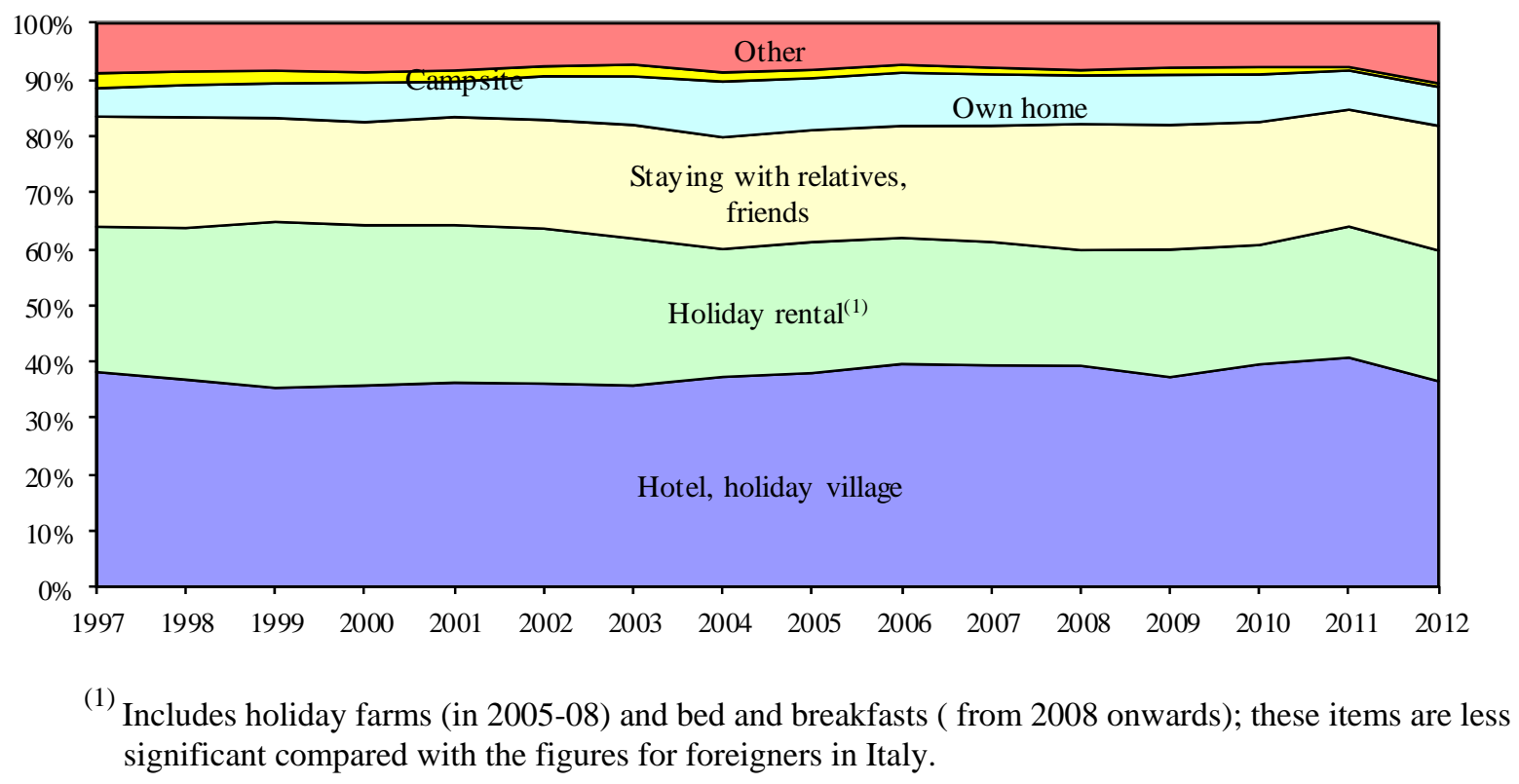

\subsection{Purpose of trips}

Holidays are the purpose most frequently cited by international travellers. Nearly 60 per cent of the overnight foreign travellers in Italy and half of the Italian overnight travellers abroad were on holiday trips. ${ }^{17}$ Holiday trips accounted for 60 per cent of total spending by foreign tourists in Italy in 2012. Since 1997 expenditure on holiday trips has grown at an average annual rate of 2.2 per cent at current prices (Table B.5). Expenditure by tourists visiting relatives or friends increased at an even faster annual pace (3.7 per cent), while that by tourists who came for other personal purposes ${ }^{18}$ grew only by 0.2 per cent per year, but with a sharp increase in 2012 (8.0 per cent).

16 A factor in the reduction in overnight stays in private accommodation was a reclassification of facilities in the survey: "holiday rentals" included holiday farms up to 2005 and bed and breakfasts up to April 2008. Net of these reclassifications, the share of private accommodation still diminished owing to the decline in overnight stays in own homes or with relatives or friends.

17 The survey distinguishes between holidays and other purposes that might be similar (honeymoons, visiting relatives or friends, shopping, spa breaks), which the survey classifies under "other personal purposes”. In the questionnaire, the question concerning the reason for the trip is: What was the purpose of your stay in Italy? Indicate the main one and any others. The interviewee can cite up to three purposes along with the main one. In this section only the main purpose will be considered.

18 Shopping, health treatments, spa breaks, religious reasons, study, honeymoon, other. 
Spending by foreign business travellers in Italy declined over the period 1997-2012, decreasing by 0.9 per cent per year. The chief factors were the drop in expenditure on business trips during the recession (see Section 5.1) and the decline in spending by seasonal workers and cross-border commuters. Business travellers in Italy account for around 20 per cent of total spending by foreign visitors, in line with the global average.

Business travellers constitute an especially profitable segment of tourism, above all because they lodge in hotels of good quality, so they spend more per day on average than other tourists. However, the amount by which their average daily expenditure exceeded that of holiday tourists declined from over 80 per cent in 1997 to 14 per cent in 2012, mainly owing to the sharp increase in business travellers from Eastern Europe, after Romania and Poland joined the European Union (Figure 6).

Figure 6

Average daily expenditure of foreign visitors by main purpose of trip, 1997-2012

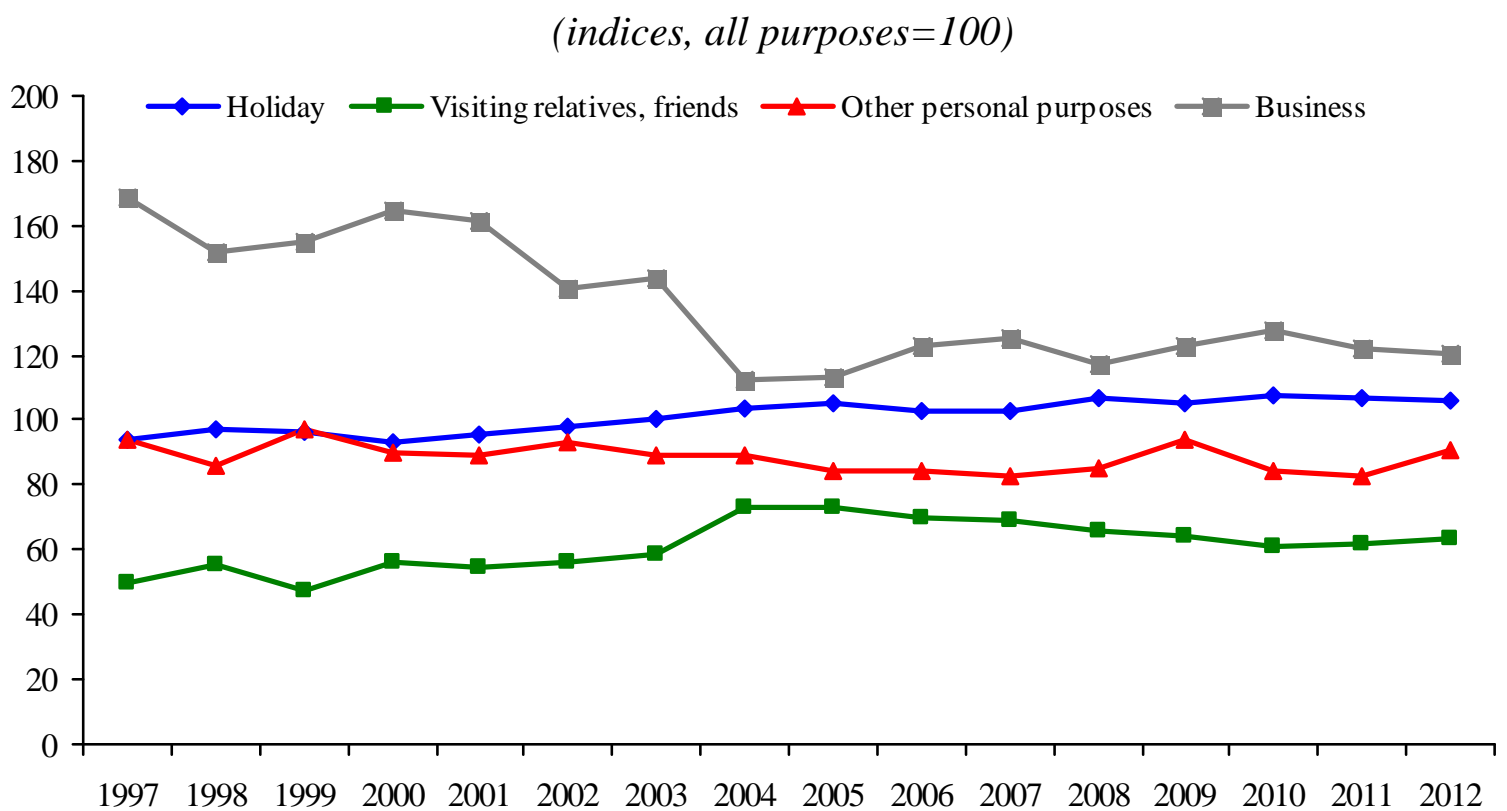

Compared with foreigners' expenditure in Italy, a larger share of Italians' expenditure abroad comes from the business component, which accounted for one third of the total in 2012; however, business travellers' share of total spending abroad has declined since 2002, when it peaked at 37 per cent (Table B.6).

Italians' holiday spending abroad grew by 2 per cent per year in the period 1997-2012, with a sharp decrease in the last year ( -12 per cent) that reflected the drop of households' consumption, and at the end of the period made up nearly 40 per cent of the total. The share of spending by persons visiting relatives or friends more than doubled, from 3.9 per cent of the total in 1997 to 8.5 per cent in 2012, with a peak of 10.2 per cent in 2008. In nominal terms this category's expenditure grew at an average annual rate of 7.6 per cent.

Since 2002 the survey contains a specific question about the type of holiday. ${ }^{19}$ Cities (i.e. cultural and arts tourism) are the preferred destination of foreign holiday travellers, accounting in

19 Only interviewees who gave "Tourism/Holiday/Leisure" as the main purpose of their trip were asked what kind of holiday they took. There are eight possible answers: seaside, mountains, lakeside, city, agritourism, sports (to practice a sport), food and wine tourism, other (cruises, cultural events, to attend a sporting event). 
2012 for 57.4 per cent of their total expenditure, followed by the seaside (18.9 per cent), lakes and mountains (8.6 and 7.2 per cent respectively). Agritourism represents a small portion of the total (2 per cent in 2012), while food and wine tourism and sports tourism account for very small shares (Figure 7).

For Italians travelling abroad, in 2012 cities and the seaside accounted for respectively 49.0 and 34.7 per cent of vacationers' total spending. The share spent at seaside resorts remained virtually unchanged with respect to 2002 up to 2010, and then fell steeply. The share spent in art cities rose rapidly between 2002 and 2007, and then increased slightly over the following five years.

Figure 7

\section{Expenditure by type of holiday, 2012}

(percentage shares)
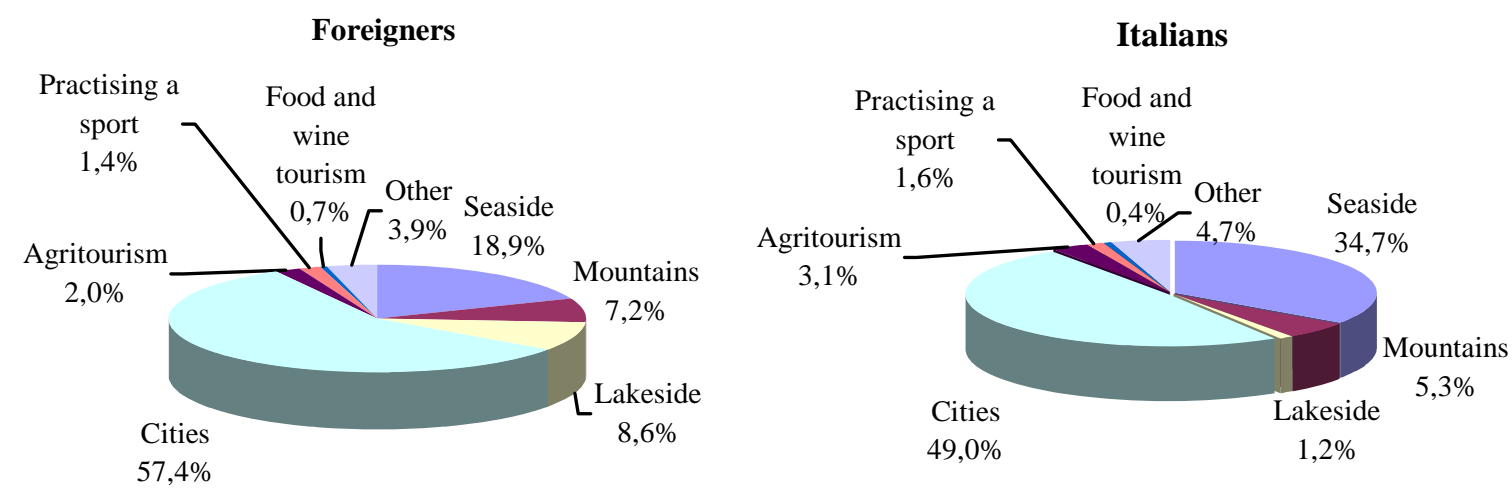

\subsection{Types of expenditure}

Since 2002 the survey has monitored the seven main types of expenditure that generally occur in an international trip: a) transport outside Italy; b) transport within Italy; c) transport between Italy and abroad; d) accommodation; e) restaurants and cafés; f) purchases of goods in shops; g) other services (museums, concerts and shows, guided tours, vehicle rental, language courses, etc.). ${ }^{20}$ The classification is useful not only for determining expenditure under the items "travel" and "passenger transport" of the balance of payments but also for research and analysis. $^{21}$

In this work, "tourism expenditure" always means expenditure comprising the items under points d), e), f), g) plus b) for foreigners and a) for Italians, in accordance with the definitions used in compiling the tourism balance of payments.

20 Before 2002, the questions on travellers' expenditure focused on the means of payment used.

21 Not all the types of transport expenditure covered by the survey are included in the item "Travel” of Italy's balance of payments, which excluded both outlays by international travellers within their own countries (e.g. taxis from/to the airport or railway station at the beginning or end of a trip) and possible travel expenses between two foreign countries. Outlays by international travellers, both Italians and foreigners, for the trip between Italy and abroad are instead included in the item "Passenger transport” of Italy's balance of payments. For a systematic treatment of the matter, see Banca d'Italia - Ufficio italiano dei cambi (2004). 
Types of tourism expenditure

(per cent; totals in millions of euros at current prices)

\begin{tabular}{|c|c|c|c|c|c|c|c|c|c|c|c|}
\hline & 2002 & 2003 & 2004 & 2005 & 2006 & 2007 & 2008 & 2009 & 2010 & 2011 & 2012 \\
\hline \multicolumn{12}{|c|}{ Foreigners } \\
\hline Transport & 9.3 & 9.5 & 10.0 & 10.0 & 10.1 & 10.8 & 10.1 & 12.6 & 12.6 & 12.3 & 12.7 \\
\hline Accommodation & 41.5 & 39.7 & 43.1 & 42.5 & 40.8 & 40.6 & 40.8 & 39.7 & 40.0 & 41.1 & 40.4 \\
\hline Restaurants & 21.8 & 21.5 & 20.9 & 20.7 & 20.7 & 20.5 & 20.7 & 20.6 & 20.6 & 20.8 & 20.9 \\
\hline Purchases & 23.3 & 25.0 & 21.2 & 21.6 & 22.7 & 22.8 & 22.7 & 21.8 & 21.3 & 20.2 & 20.1 \\
\hline Other & 4.1 & 4.3 & 4.8 & 5.3 & 5.6 & 5.3 & 5.6 & 5.3 & 5.5 & 5.5 & 5.8 \\
\hline Total & 28,207 & 27,622 & 28,665 & 28,453 & 30,368 & 31,121 & 30,368 & $\mathbf{2 8 , 8 5 6}$ & 29,257 & 30,891 & 32,056 \\
\hline \multicolumn{12}{|c|}{ Italians } \\
\hline Transport & 11.6 & 12.1 & 12.3 & 13.5 & 14.0 & 13.6 & 14.0 & 15.0 & 14.5 & 14.0 & 14.7 \\
\hline Accommodation & 45.5 & 43.4 & 44.6 & 44.1 & 42.6 & 42.8 & 42.6 & 40.2 & 40.1 & 42.4 & 43.2 \\
\hline Restaurant & 23.2 & 23.6 & 21.0 & 20.9 & 21.0 & 21.5 & 21.0 & 20.9 & 21.8 & 21.3 & 20.5 \\
\hline Purchases & 13.1 & 13.8 & 15.8 & 15.0 & 15.4 & 15.0 & 15.4 & 16.3 & 15.9 & 15.0 & 14.2 \\
\hline Other & 6.6 & 7.2 & 6.3 & 6.5 & 7.0 & 7.1 & 7.0 & 7.5 & 7.7 & 7.3 & 7.3 \\
\hline Total & 17,811 & 18,236 & 16,515 & 18,001 & 18,399 & 19,952 & 18,399 & 20,015 & 20,416 & 20,583 & 20,512 \\
\hline
\end{tabular}

The share of each component in the total is quite stable over time (Table 4). Accommodation $^{22}$ is the largest item: its share was consistently around 40 per cent for foreigners in Italy and is slightly higher, fluctuating between 40.1 and 45.5 per cent, for Italians abroad. For Italians and foreigners alike, the share of spending for accommodation diminished in 2009 and then rose back over the years 2011-2012. During the most acute phase of the crisis, travellers preferred more economical forms of accommodation to hotels and holiday villages. ${ }^{23}$ Spending on purchases of goods and services fluctuated around 22 per cent for foreigners between 2005 and 2008 and trended downwards in the last four years, while it remained stable at around 15 per cent for Italians. The third-largest item - restaurants and cafés - ranged between 20.5 and 21.8 per cent of the total for foreigners and between 20.5 and 23.6 per cent for Italians. Partly owing to the rise in prices for fuels and transport services, spending for transport increased in the last three years to make up more than 12 per cent of foreigners' total expenditure. For Italians going abroad, transport ranged between 12 and 16 per cent of total outlays.

\subsection{Means of transport}

Two thirds of the foreigners who visited Italy in 2012 entered the country by road, 81 per cent of them in a car. The remaining tourists arrived mostly by air. Very few foreign tourists entered Italy by rail or ship.

The expenditure of tourists travelling by air exceeded that of those travelling by car, since the latter include a large number of day trippers, who spend little; day trippers make up about 60 per cent of the inbound and 80 per cent of the outbound tourists who cross the border by car. In 2012 the expenditure of the foreigners who arrived in Italy by air accounted for 57 per cent of the total, compared with 39 per cent for those who travelled by car; the corresponding figures for Italian tourists abroad were 72 and 24 per cent, reflecting their greater propensity to take long-

22 Accommodation expense includes spending for meals at the accommodation establishment used (e.g. breakfast, full board or half board).

23 See Section 5. 
distance trips (Figure 8). Tourists who entered/left by rail or ship accounted for a very small fraction of total expenditure.

Figure 8

Expenditure by means of transport used, 2012
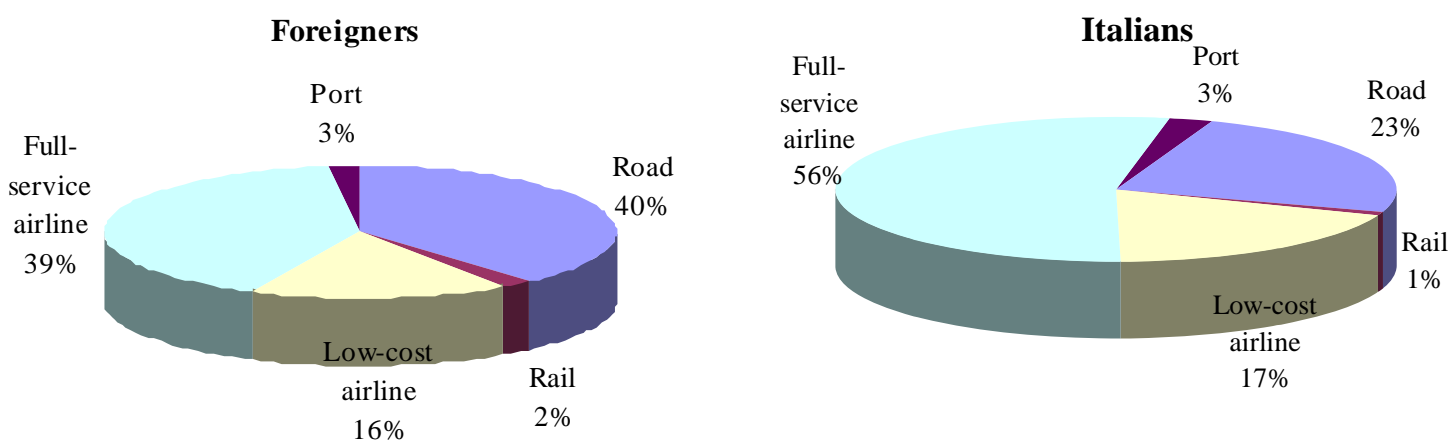

Travel by air increased its share over the period under review at the expense of travel by car, which up to 2000 was the means of transport chosen by three quarters of travellers. The expansion of air travel's share from 15 per cent in 1997 was driven by the growth of low-cost flights, which was particularly intense in Italy. Starting in 2004 the survey offers information on the percentage of travellers and the share of total expenditure of tourists who flew with low-cost airlines to and from Italy: between 2004 and 2012 their share of total expenditure more than doubled from 7 to 17 per cent (equal respectively to 13 and 28 per cent of the expenditure of tourists who travelled by air). The average expenditure of those coming to Italy by low-cost airlines was almost a third less than that of other air travellers, and the average duration of their trip was slightly shorter. The explanation is twofold: first, low-cost flights carry a smaller share of business travellers, who generally spend more; second, many low cost trips are week-end short breaks.

\subsection{Travellers' opinions of the destination of their trip}

The survey also provides information on travellers' satisfaction during their trip. Interviewees ${ }^{24}$ were asked to rate the place they visited in nine respects ${ }^{25}$ on a scale ranging from 1 (very poor) to 10 (excellent) and to offer an overall judgment.

In 2012, foreigners in Italy awarded the country an average overall score of 8.4, while Italian travellers abroad awarded their destinations an average overall score of 8.1 The difference between the two overall assessments declined over the period under review: in 1997 foreigners' assessment of Italy (8.3) had been virtually the same as in 2012, while Italians had awarded their destinations an average score of 7.8 (Figure 9).

24 These exclude cross-border commuters and include day trippers. But since the latter are not in a position to evaluate some of the items (for example, quality of accommodation facilities), they are not considered in the analysis in this section.

25 Interviewees are asked to rate the following: a) reception and friendliness of the population; b) cities and works of art; c) landscape, natural environment; d) accommodation; e) meals; f) prices; g) quality and variety of products in shops; h) tourist information and services; i) tourists’ safety. They also give an overall score. 
Figure 9

\section{Opinions on some aspects of trips, foreigners and Italians, 1997 and 2012}

(average scores)
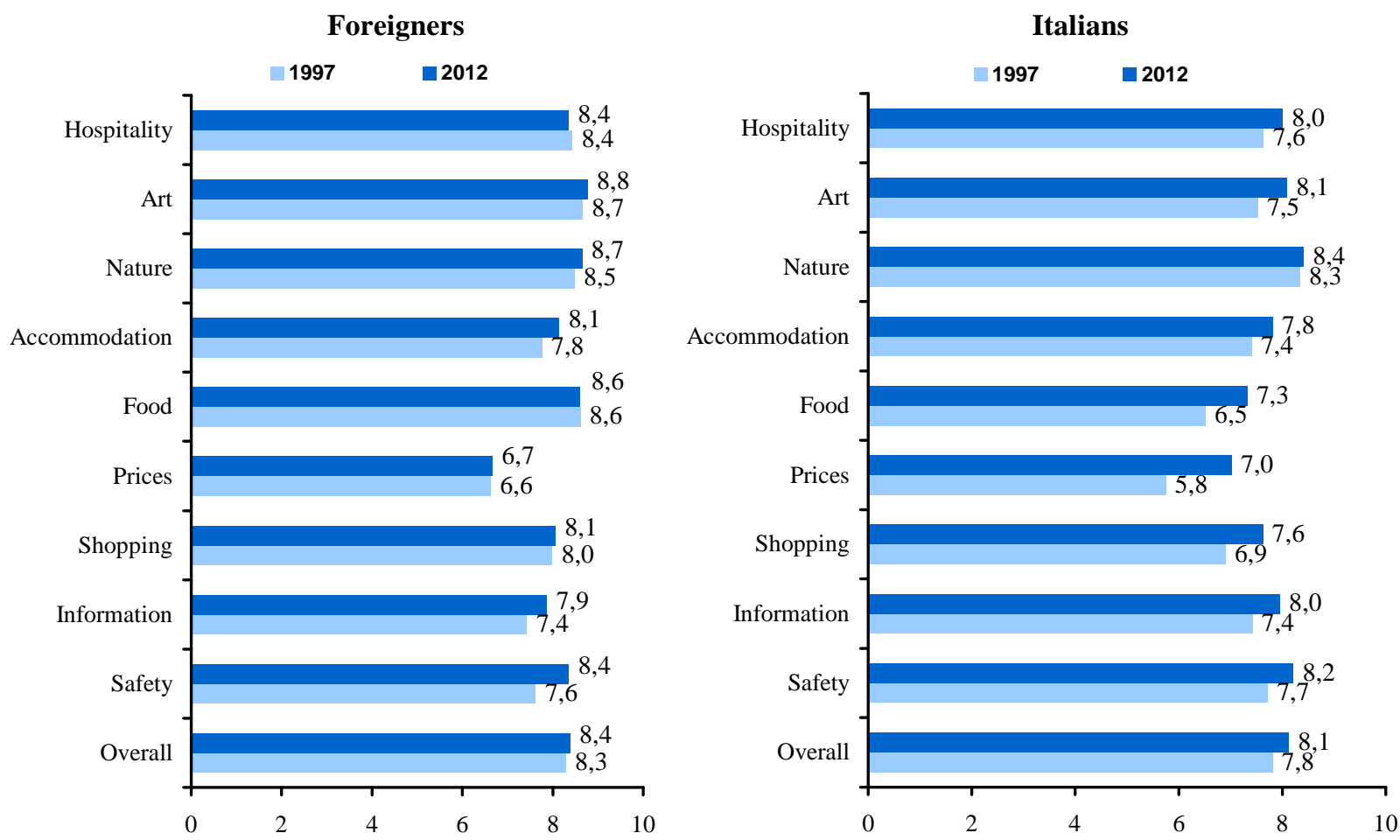

The aspects of their experience in Italy that foreigners prized most highly were art, nature and food, to which they assigned an average score of about 8.5. Italian travellers abroad particularly appreciated nature and safety (scores above 8).

Prices were the aspect of trips that attracted the least favourable judgment among both foreigners and Italians. In 2012 prices were the only item for which Italians assigned a higher score than did foreigners. Foreign travellers' assessments of prices in Italy have remained practically unchanged since 1997, while Italians tourists' opinions concerning prices abroad have improved.

Food is another point on which Italians abroad are rather critical, though less so over the years (with a score of 6.5 in 1997 and 7.3 in 2012). The supply of tourist information and services attracted similar assessments from Italians and foreigners. Finally, foreigners' opinions of the safety of a vacation in Italy improved (from 7.6 in 1997 to 8.4 in 2012). In 2012 the highest score for safety was awarded to the North-East (8.5), the lowest to the North-West (7.9). 


\section{Tourism during the recent crisis $^{26}$}

\subsection{Foreign tourism in Italy}

A comparison with France and Spain. - Late in 2008 international tourist flows began to feel the repercussions of the economic and financial crisis. In Italy, tourism receipts at current prices stagnated, slipping by 0.1 per cent for the year; while in Spain (-0.4 per cent) and especially France (-2.9 per cent) they fell. The decline steepened in 2009 in all three countries (-7.2 per cent in Italy, -7.7 per cent in France and -9.0 per cent in Spain). Italy and Spain staged a modest recovery in 2010, gaining 1.4 and 3.9 per cent respectively, while France only stopped the fall in receipts (-0.1 per cent). In 2011 the recovery strengthened, most notably in France, then it slowed down in 2012, reflecting the weaker demand from European and other advanced economies. The three countries eventually recouped all of their nominal losses: in 2012 Italy's receipts at current prices were 3.0 per cent higher than in 2007; in terms of chain-linked volumes, however, receipts were still 8.0 per cent lower than in 2007. As to the two competitor countries, Spanish tourism receipts at current prices were 3.5 per cent above their pre-crisis level, French receipts 5.5 per cent above (Figure 10); ${ }^{27}$ but, in terms of volumes, in 2012 Spanish and French receipts were respectively 6.1 and 2.8 per cent below their pre-crisis levels.

Figure 10

\section{Receipts from international travel during the crisis in France, Italy and Spain}

(current prices; indices, 2007=100)

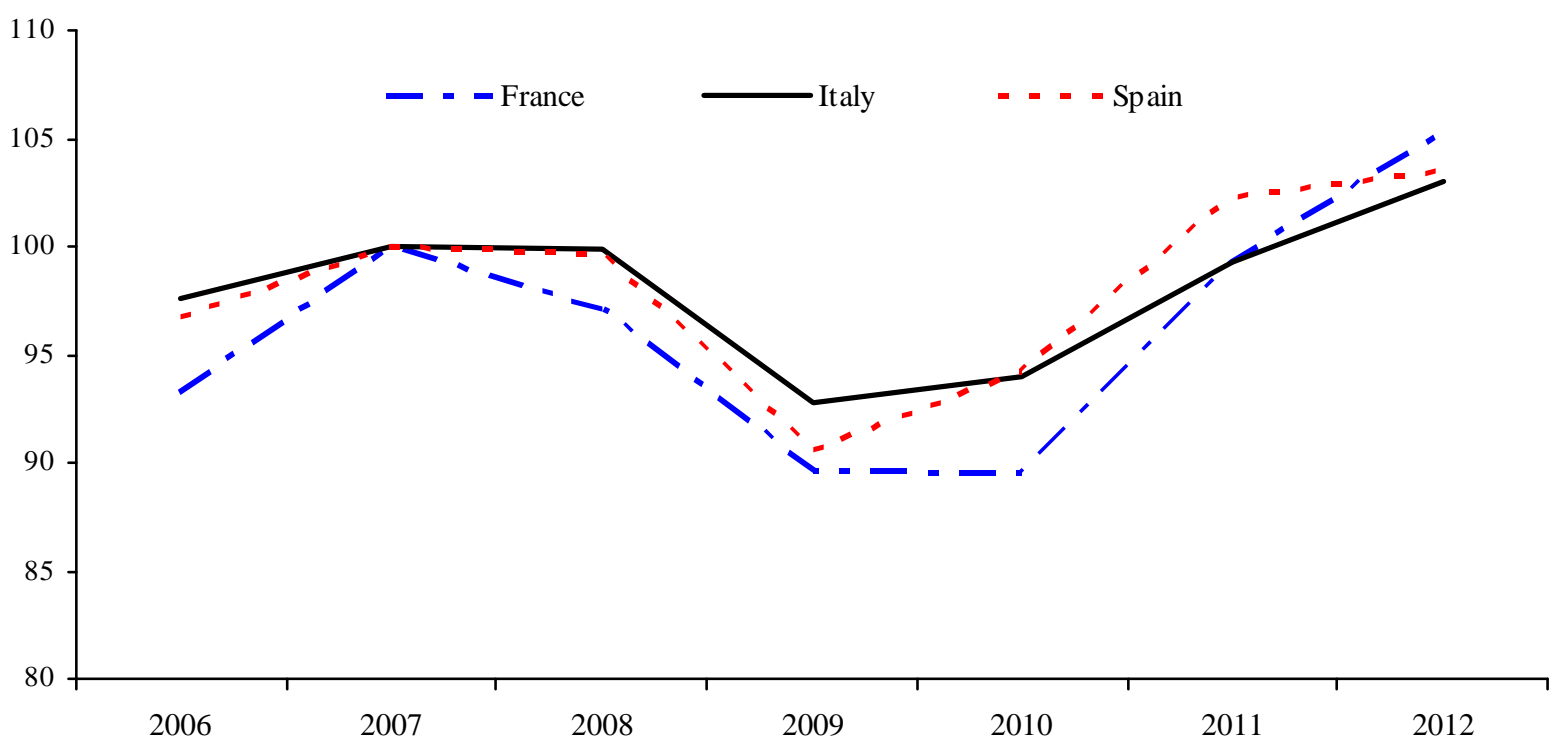

Sources: based on Bank of Italy and Eurostat data.

This section updates Alivernini and Breda (2010).

The three countries' receipts from seaside tourism were favoured in 2011 by the political instability on the Southern shore of the Mediterranean, notably in Egypt, which had become an important seaside destination for European tourists. 
Since 2008, as tourist demand declined, the prices of hotel services diminished (or rose more slowly than in previous years and than the consumer price index) in Spain and especially in Italy, while in France they continued to grow at about the same pace as before the crisis, and faster than the average rate of consumer price inflation (Figure 11).

Figure 11

\section{Price competitiveness of Italy versus France and Spain ${ }^{(1)}$}

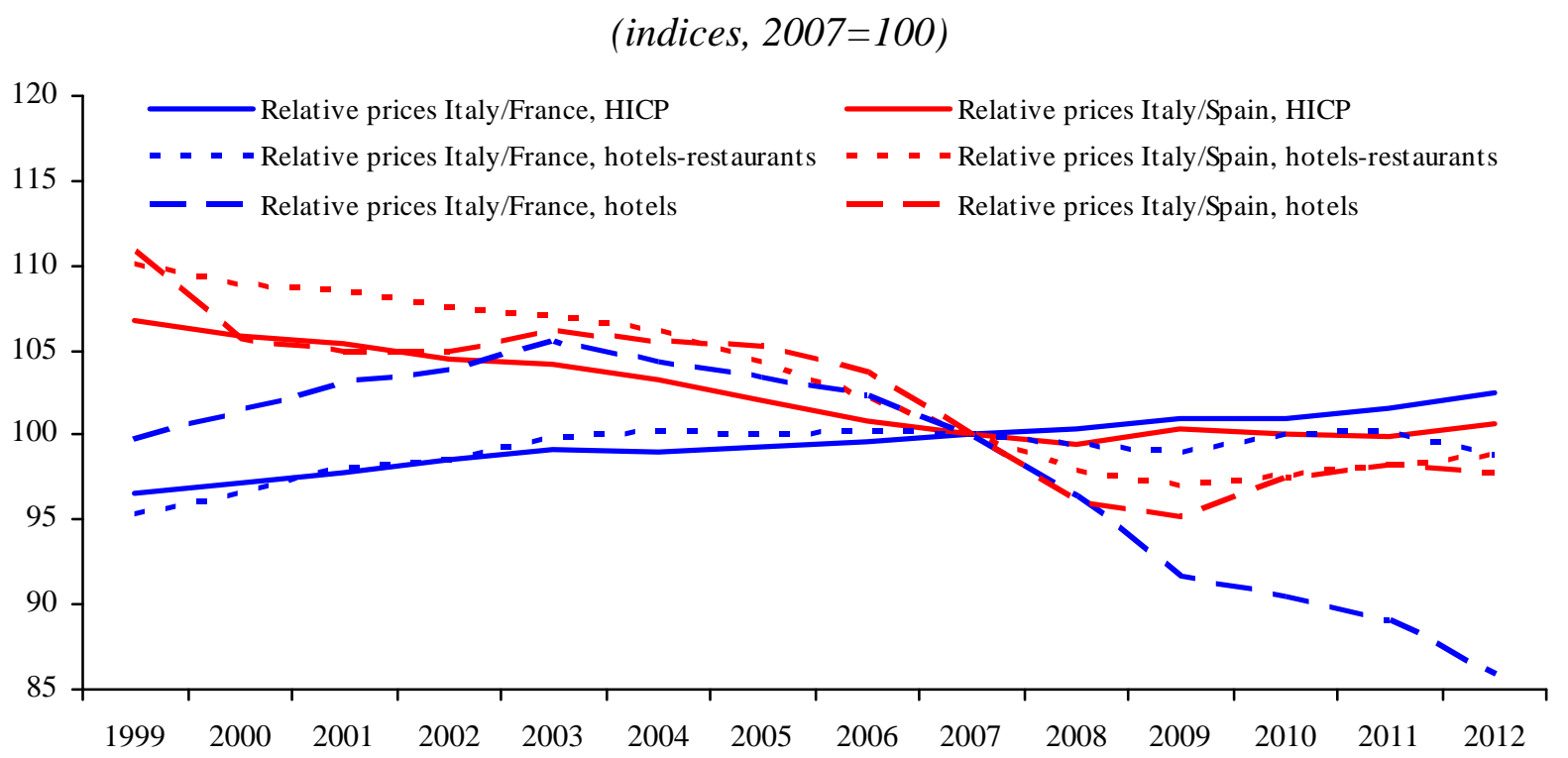

Source: based on Eurostat data.

(1) Ratio of harmonized price indices in Italy for all consumer goods and services (HICP), hotels and restaurants, and hotels only, to the corresponding indices in France and Spain; an increase in the ratio indicates a decline in Italy’s price competitiveness.

The relatively poor performance of French tourism receipts between 2008 and 2010 would appear to be explained, at least in part, by the pricing policies adopted by French hotels, which practically did not react to the fall in demand until $2010 .^{28}$ However, in the two following years the recovery of receipts was stronger in France than in Italy and Spain, apparently without a clear change in the pricing policies of French hotels. The comparison between Italy and Spain produces slightly more clear-cut conclusions. In 2009, at the height of the international crisis for the world economy and for the tourism industry, the average prices of hotel rooms fell more rapidly in Italy than in Spain (by 2.4 against 1.4 per cent), and tourism receipt losses were larger in Spain than in Italy. In 2010-12, on the contrary, there was at least a temporary halt to the gain in Italy's competitiveness vis-à-vis Spain, which had been under way for most of the preceding decade, and as a matter of facts the recovery of receipts was faster in Spain. ${ }^{29}$

28

insly the price of hotel services is not the sole determinant of travellers' choices of destination, but accommodation is one of the main expense items (for foreign travellers in Italy, for instance, it accounts for more than 40 per cent of the total cost of the trip, net of international transport; see Table 2). In 2009-10 Spanish economy-wide inflation (HICP) fell sharply. 
Tourism receipts in Italy. - Trends in international tourism receipts in the Italian macroregions since 2006 have been diversified. ${ }^{30}$ The tourism receipts of the North-East, after falling in 2007 mainly due to poor skiing conditions, rose again in 2008 (when instead receipts began to stagnate nationwide). The decline in 2009 was less sharp than the national average, by 2010 the North-East's receipts had practically regained their 2007 level, and in 2012, at current prices, they were 11 per cent higher (Figure 12). For the Centre, the macro-region with the most tourism receipts, the fall in 2009 was sharper than the national average, but so was the upturn in the next two years, and in 2012, receipts were slightly above the pre-crisis level, as in the North-West. By contrast in the South and Islands tourism receipts at current prices were still almost 4 per cent lower in 2012 than in 2007. In the South and Islands receipts were already on the way down in 2007, and the decline continued until 2010, confirming the region's competitive difficulties. The supply-side impetus provided in the course of the last decade by the increasing availability of low-cost flights and improvements in the quality of accommodation as well as an increase in the number of beds appears to have faded. ${ }^{31}$

Figure 12

\section{Foreign tourist spending in Italy during the crisis by macro-region}

(current prices; indices, 2007=100)

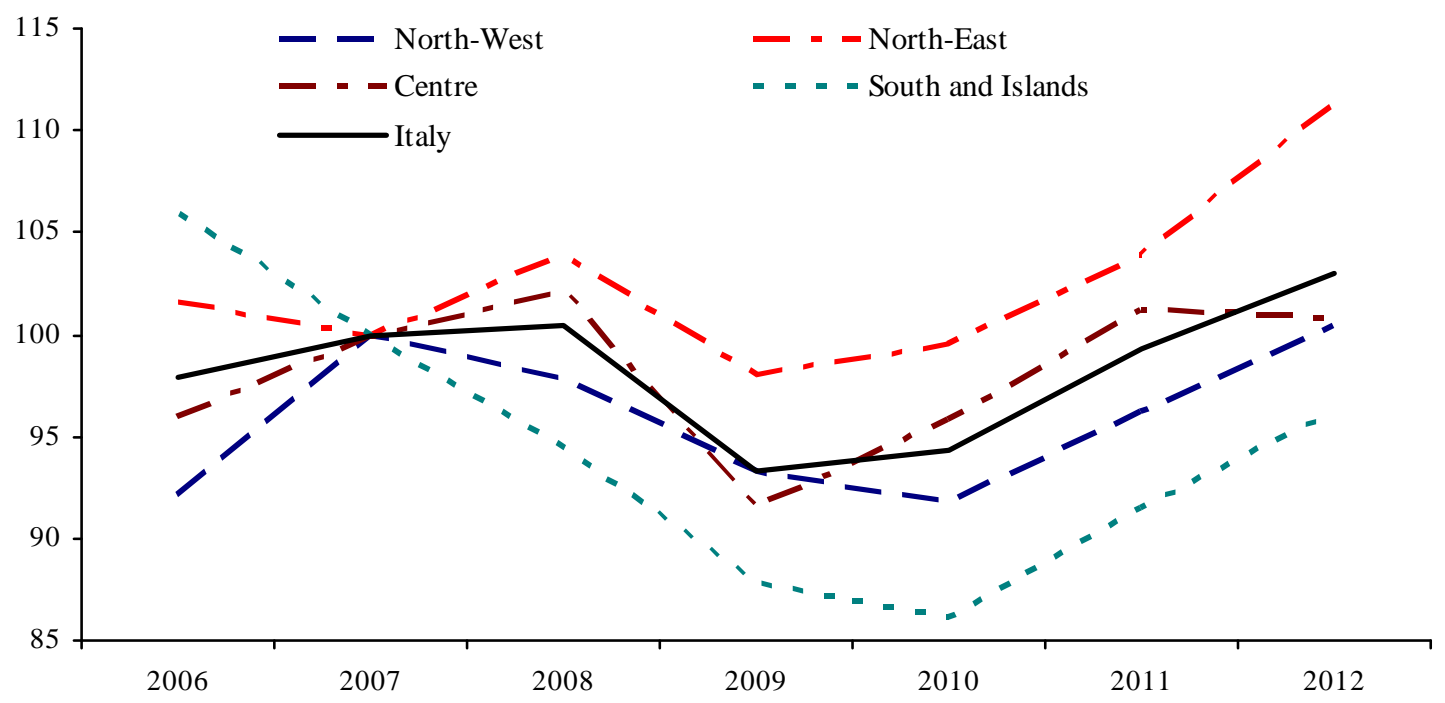

Furthermore, in the early stages of the crisis foreign travellers in Italy appear to have partially and temporarily switched from hotels (and holiday villages) to other types of accommodation. In 2008, spending by tourists not staying in hotels increased and in 2009 it fell by less than the expenditure of those staying in hotels and holiday villages. In 2010-11 the latter turned back up more sharply, regaining pre-crisis levels at current prices (Figure 13).

For medium- and long-term trends in foreign tourism receipts by region in Italy, see Alivernini, Gallo et al. (2012).

31 See Alivernini, et al. (2013b) and the special feature "Il turismo delle regioni italiane" in Banca d'Italia (2011). 
Figure 13

\section{Foreign tourist spending in Italy during the crisis by type of accommodation}

(current prices; indices, 2007=100)

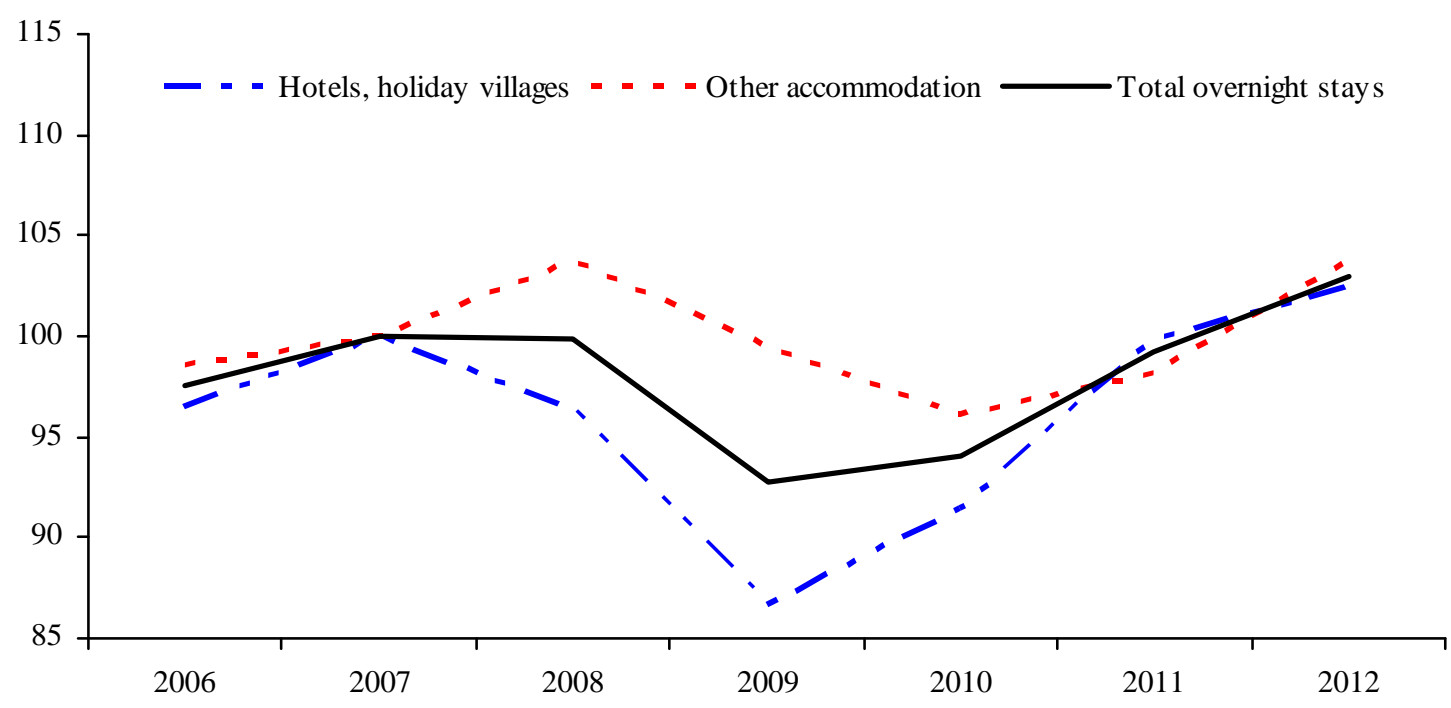

The relative performance of receipts according to type of accommodation also depends on the purposes of trips. The decline in the spending of tourists who stayed in hotels and holiday villages in 2008-09 was due in part to a temporary modification of the "personal" reasons for travel. In these two years there was an increase in spending on travel for "other" reasons (not holidays), and specifically to visit friends or relatives (which ordinarily means staying as guests at their homes). In 2009 especially there was a recession-related fall in spending on business trips, which was borne almost entirely by hotels, business travellers' normal accommodation of choice. In 2010-11, spending for holidays and other personal purposes regained pre-crisis levels and in 2012 it kept growing, whereas business trip spending, which began to fall again with the new economic slowdown, was 10 per cent below its 2007 level in nominal terms (Figure 14). 


\section{Foreign tourist spending in Italy during the crisis by purpose of trip}

(current prices; indices 2007=100)

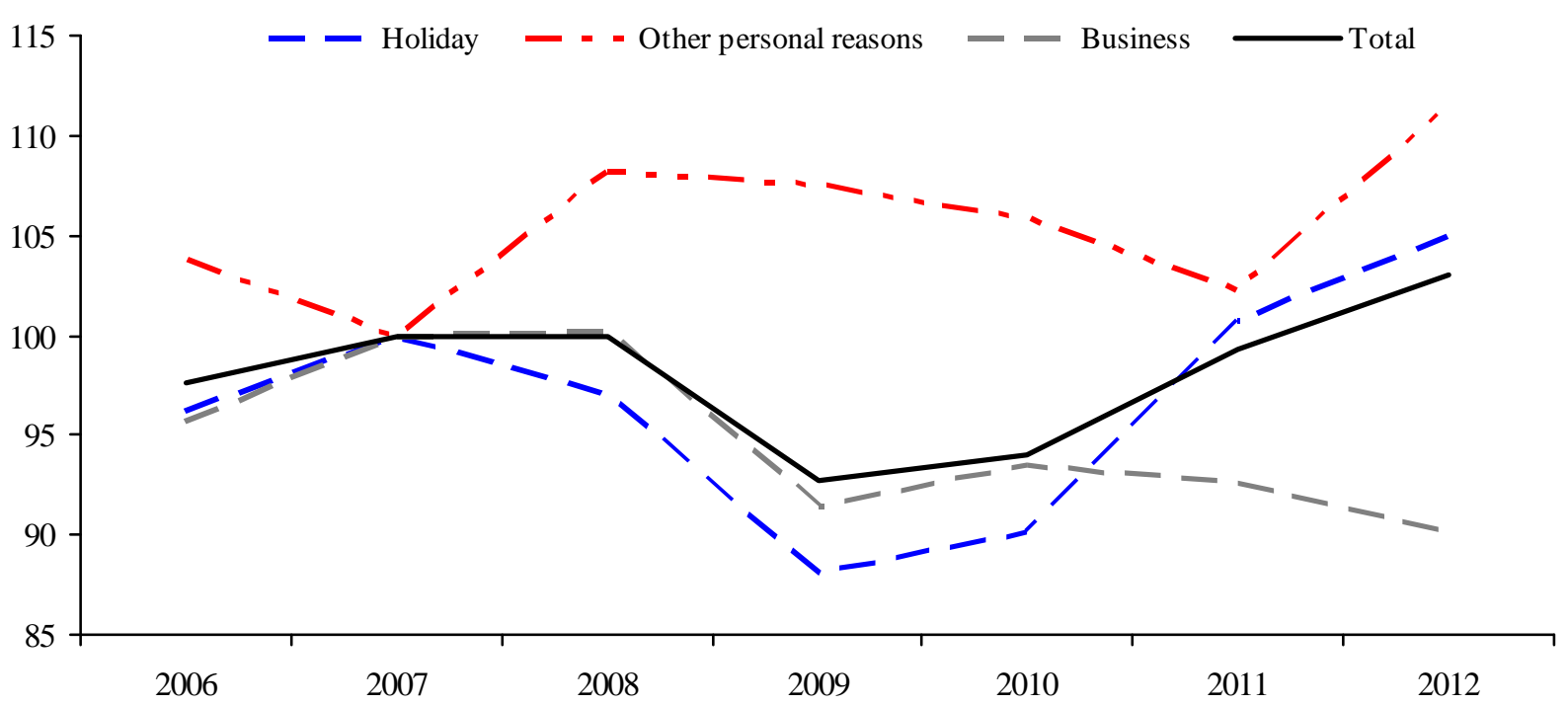

\subsection{Italian tourism abroad}

Italians' spending abroad diminished by 4.3 per cent in 2009 with respect to the previous year (4.1 per cent in terms of chain-linked volumes). The fall was much less steep than in 199394, when total expenditure fell by nearly 3 per cent per year at current prices and 15 per cent per year in terms of chain-linked volumes. The effects of the 1993 recession were compounded by the sharp depreciation of the lira in September 1992, which for a time drastically undercut the competitiveness of foreign destinations (Figure 15). In 2009, by contrast, there was some tendency to replace tourism within Italy by foreign trips, ${ }^{32}$ which gained competitiveness thanks to the decline in airfares and other travel costs that year. ${ }^{33}$ But unlike the situation in the early 1990s, the subsequent recovery was very feeble: Italians' spending abroad rose by just 1.4 per cent per year at current prices in 2010 and 2011, and declined by 2.9 per cent per year in terms of chain-linked volumes.

After a moderate increase between the second quarter of 2010 and the first half of 2011, Italians' spending abroad contracted again in the second half in concomitance with the sovereign debt crisis and the steep decline in Italian consumer confidence, which in the final months of 2012 reached historically low levels. As a matter of fact, in 2012 Italians' spending abroad decreased by 0.3 at current prices and by 4.2 per cent in terms of chain-linked volumes. ${ }^{34}$

32 According to a survey conducted by Istat, the number of trips by residents within Italy fell by 9.4 per cent between 2008 and 2009, while the number of foreign trips remained practically unchanged (see Istat, 2010). Istat's index of airfares (domestic and international) fell by 13 per cent in 2009.

34 According to Istat's survey, the decrease in domestic trips was even larger (Istat, 2013). 
Figure 15

Italian expenditure on foreign travel and household consumption, 1971-2012

(percentage changes on previous year)

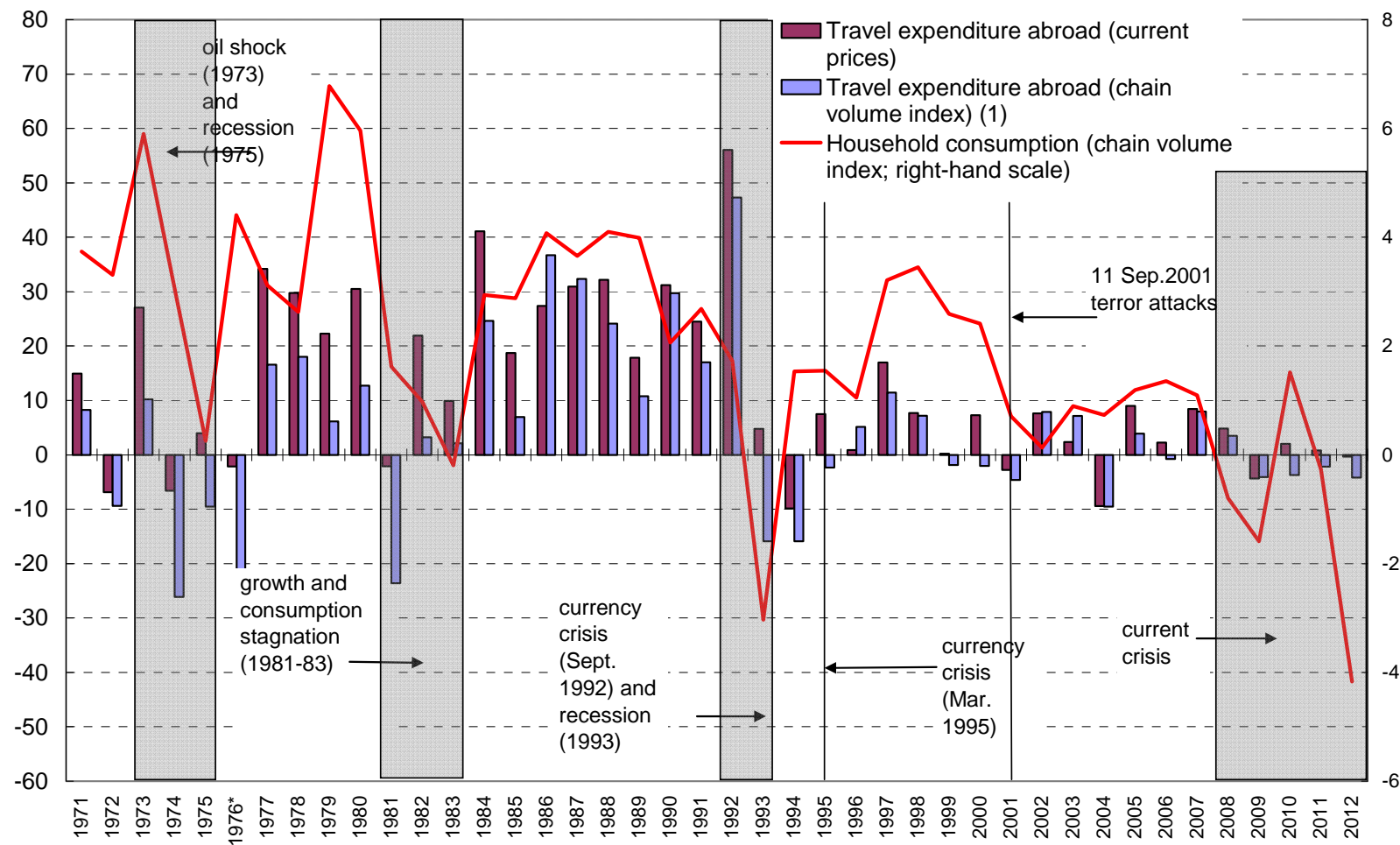

Sources: based on Bank of Italy and Istat data.

(1) Deflated using the deflator of residents' consumption abroad.

${ }^{(*)}$ Break in the travel expenditure series.

Like foreign tourists in Italy, some Italian travellers abroad also shifted temporarily from hotels to other, generally less expensive, accommodation in 2009. The trend faded in 2010, and in 2011 the spending of travellers who stayed in holiday villages or hotels was 6.1 per cent more than in 2007, at current prices, while that of tourists staying in other accommodation was 5.3 per cent less (Figure 16). What modest recovery in spending there was in 2010 and 2011 (at current prices) would thus appear to have been led by the more affluent. As Italians' expenditure started to decline again in 2012, there was a new shift from hotels to other accommodation that was even more pronounced than in 2009. 
Figure 16

\section{Italian tourist spending abroad during the crisis by type of accommodation}

(current prices; indices, 2007=100)

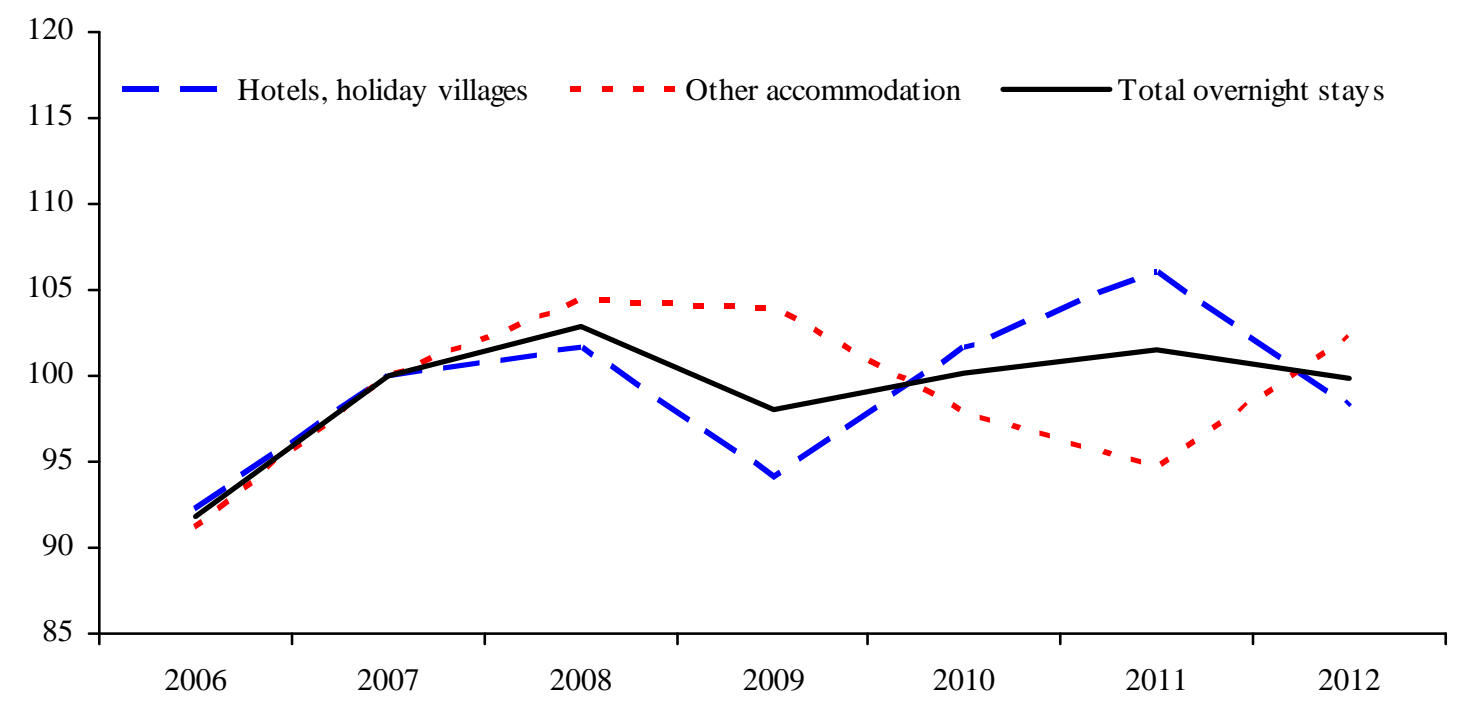

\section{Conclusion}

With its unparalleled historical, artistic and cultural heritage, Italy enjoys one of the world's greatest collections of tourist attractions, in particular its cities rich in art and culture and its many religious sites. ${ }^{35}$ International travel is the only item in Italy's balance of payments on current account that has always produced a surplus. Nevertheless, over the past sixteen years trade in tourist services has made a negative contribution to Italian GDP growth, as receipts from foreign tourism have diminished in real terms while Italians' spending abroad has remained basically unchanged.

Over this period the range of tourist destinations around the world has broadened, while the real cost of air travel for holiday and other personal purposes has declined, and in more recent years business travel budgets have been tightened. These factors have resulted in a decreased contribution to the growth of tourism receipts from the high-income countries that have been the traditional places of origin of visitors to Italy. ${ }^{36}$ This reduction has been more than offset in terms of arrivals, but not overnight stays or receipts, by travellers from the new EU Member States of Central and Eastern Europe, who spend less per capita and per day than tourists from the EU-15 and the other advanced economies. The share of spending and tourist presences accounted for by travellers from the BRIC countries - with the partial exception of Russia - is still small, although growing. These large and rapidly-expanding economies represent the greatest potential for growth in the tourist sector too.

35 Italy is the leader in UNESCO world heritage sites, with 49 (45 cultural and 4 natural) out of the total of 981 in 2013.

36 In particular, the expenditure share of German and Japanese tourists has decreased markedly. The former have been increasingly drawn to other seaside destinations in the Mediterranean, while the latter have cut down on travel generally, given the protracted stagnation of the Japanese economy. 
In the earlier stage of the recent crisis (2008-09), the fall of international tourism receipts was less intense in Italy than in Spain or France; over the years 2011-12, the recovery of the latter was stronger. In 2012, the three countries' receipts at current prices were higher than their pre-crisis levels; however, receipts at constant prices were still well below the 2007 levels (8.0 per cent for Italy).

Within Italy, the contribution of the South to tourist earnings remained limited, despite the region's notable artistic, cultural and landscape endowment and the potentially longer seaside vacation season than in the rest of the country. In 2012 the South's tourism receipts accounted for just 13 per cent of the national total and around 1 per cent of the area's GDP, half the percentage of the Centre and North. In fact, after gaining ground with respect to the Centre and North in the early 2000s, thanks to the growing presence of low-cost airlines, which reduced the relative disadvantage in accessibility, and despite investment in improving hotel quality, the South is the macro-region where receipts fell most steeply in the recent crisis.

Between 1997 and 2012 expenditure by Italians abroad at constant prices (i.e., imports of travel services) expanded at a yearly average rate of 0.2 per cent, remaining practically unchanged as a share of GDP (declining from 1.4 per cent in 1997 to 1.3 per cent in 2012). However, during the recent crisis expenditure abroad increased on average by just 0.6 per cent per year at current prices and decreased on average by a yearly 2.2 per cent at constant prices. So far, the fall of expenditure at constant prices has been much less pronounced than that observed during the 1992-95 currency crises: at that time the lira's depreciations greatly decreased the competitiveness of foreign destinations and caused a steep increase in price deflators. Moreover, during the recent crisis the fall in the number of domestic trips was more pronounced than that of foreign trips.

The importance of promoting tourism in Italy is evident. Promotional campaigns will be especially useful in moving into markets that are "distant" both geographically and culturally (such as China and India), and this activity needs to be better coordinated at national level. ${ }^{37}$ Apart from promotion, fuller exploitation of the South's tourist potential will depend on improving accessibility. ${ }^{38}$

37 The OECD's recent study of tourism in Italy (OECD, 2011) lists improving coordination and enhancing the effectiveness of tourist promotion and public financing as priorities for development of the sector, as well as systematic assessment of funding's effectiveness.

According to foreign travellers' ratings, safety is also often a disadvantage for the South compared with the Centre and North; however, it must be noted that in 2011-12 the safety ratings given to the South were higher than those given to the North-West. 


\section{References}

Alivernini, A. (2012), "Una valutazione delle spese turistiche fra il Centro Nord e il Mezzogiorno (1998-2008)”, in Rivista di economia e statistica del territorio, No. 1.

Alivernini, A., Breda, E. (2010), "Il turismo in Italia ai tempi della crisi”, La Rivista del Turismo, Vol. 2, pp. 4-13.

Alivernini, A., Breda, E., Iannario, E. (2013a), "Quindici anni di turismo internazionale dell'Italia (1997-2011)”, in Il turismo internazionale in Italia: dati e risultati, Workshop and Conferences, No. 12, Banca d'Italia.

Alivernini, A., D’Ignazio, A., Migliardi, A. (2013b), “L’impatto dei voli low-cost sulla spesa turistica degli stranieri in Italia ", in Il turismo internazionale in Italia: dati e risultati, Workshop and Conferences, No. 12, Banca d'Italia.

Alivernini, A., Gallo, M., Mattevi, E., Quintiliani, F. (2012), “Tendenze del turismo internazionale nelle regioni italiane”, in Rassegna Economica, No.1.

Alivernini, A., Santoro, M. T. (2010), "Italy's official statistics on inbound tourism: a comparative analysis of supply and demand side sources", presented at the " $10^{\text {th }}$ International forum on tourism statistics”, Lisbon, 22-23 November 2010.

Banca d'Italia (2011), “L'economia delle regioni italiane. Dinamiche recenti e aspetti strutturali”, Economie regionali, No. 23.

Banca d'Italia - Ufficio italiano dei cambi (2004), Manuale della bilancia dei pagamenti e della posizione patrimoniale sull'estero dell'Italia, Roma.

IMF (1993), Balance of payments manual, 5th edition.

IMF (2009), Balance of payments manual, 6th edition.

IMF (2014), World economic outlook update - Is the tide rising?, January.

Istat (2010), “Viaggi e vacanze in Italia e all'estero - Anno 2009”, Statistiche in breve.

Istat (2013), “Viaggi e vacanze in Italia e all'estero - Anno 2012”, Statistiche in breve.

Istat, Banca d'Italia, Ciset, Dipartimento per lo Sviluppo e la Competitività del Turismo, Osservatorio Nazionale del Turismo (2012), "Il primo conto satellite del turismo per l'Italia”.

OECD (2011) OECD studies on tourism - Italy: Review of issues and policies.

OECD (2012), OECD Tourism Trends and Policies 2012.

Sudman, S., Bradburn, N. M. (1973). 'Effects of Time and Memory Factors on Response in Surveys', Journal of the American Statistical Association, Vol. 68 (344), pp. 805-815.

UNWTO (2013) World Tourism Barometer, Vol. 11, April. 


\section{Appendix A - Methodological notes}

A1. The item "travel" of the balance of payments: definitions and the switch from the fifth to the sixth edition of the IMF manual

To gather and disseminate data on the balance of payments (and therefore also on the transactions involved in international travel) is one of the tasks traditionally entrusted to central banks. The collection of the data needed to compile the balance of payments is subject to the principle of subsidiarity, whereby each country can choose the method of collection best suited to its economic and social characteristics.

Until 1995 Italy obtained the information needed to compile the item "travel" of the balance of payments from the data on bank settlements of purchases and sales of banknotes, supplementing them with information on expenditure made using other means of payment (credit cards, traveller's cheques and bank credit transfers). Banks as a source of data nonetheless suffered from methodological problems, including:

- the underestimation of gross flows, owing to the clearing that occurred between banks;

- the imperfect geographical allocation, due to the association made between the foreign currency acquired and the country in which it was legal tender;

- the impossibility of carrying out the disaggregation typical of tourism statistics (accommodation, reason for and duration of travel, socio-demographic characteristics of the traveller, etc.).

The entry into effect of euro banknotes, scheduled for 2002, would have made it impossible to use the banking industry as the source of data on transactions with the other euro-area countries, which had always accounted for the greater part of the transactions involving international travel. It was therefore decided to look for an alternative observation method, able to overcome the problems referred to above and improve the quality of the tourism account.

Accordingly, since 1999 the Italian balance of payments has been compiled and published in accordance with the ESCB harmonized standard and the fifth edition of the IMF's balance-ofpayments manual (BPM5). This scheme is marked by its consistency and integration with the System of National Accounts. The item "travel", together with "transport" and "other services"39, constitute the item "services" of the current account.

In 1996 the survey on Italian international tourism was launched with the aim of compiling the item "travel" in the balance of payments. The survey was intended to achieve a dual objective. Firstly, to improve the quality of the statistics of the tourism account and increase their conformity with international standards. Secondly, to provide users with analytical information on numerous aspects of the inbound and outbound tourist markets, in addition to that strictly necessary for the compilation of the balance of payments.

Both in BPM5 and in BPM6 (IMF, 2009), which will be adopted by Italy and the other EU countries in June 2014, the item "travel" is made up of a heterogeneous set of goods and services acquired in the economy being visited by persons in countries of which they are not residents (during stays in such countries lasting less than one year), with the exclusion of international transport services, goods and services acquired for commercial purposes by business travellers

39 See footnote 6. 
on behalf of the firm of which they are part or in any case for purposes other than direct use by the traveller. The persons in question, since they are travelling at the conditions referred to above, are known as "travellers".

The item "travel" essentially reflects the economic effects of tourism into a country (known as "inbound tourism" in tourism statistics), comprising the stays of non-residents, and tourism out of that country ("outbound tourism"), comprising the stays of residents abroad. The economic transactions generated by inbound and outbound tourism are matched, respectively, by the credits and debits under "travel" in the balance of payments. This "transversal effect" is a distinctive feature of the travel industry, which is identified less by the characteristics of what it produces than by the nature of the persons who generate the demand.

The concept of tourism referred to here is that used in the sector statistics and the national accounts. While in common parlance the term "tourism" is essentially synonymous with "holidays", here it is taken to mean the broader economic phenomenon triggered by persons who move outside their habitual environments for a wide variety of reasons and generally for a period of less than one year. It follows, for example, that the item "travel" refers not only to "personal travel" but also to "business travel".

There are some exceptions to the rules described up to this point; the first concerns the limit of one year on the length of stays. It is ignored, in fact, for persons who travel for healthand study-related reasons. Such persons are always considered travellers, so that their consumption is included under travel, even if the stay abroad lasts for more than a year. According to the rules of the fifth and sixth manuals, in fact, such persons continue to be residents of their country of origin because their centre of economic interest remains there.

The second exception is valid for cross-border and seasonal workers who have travelled to engage in a job for an entity resident in the economy being visited; for the latter in fact there is a derogation from the traveller-travel one-to-one correspondence. Although cross-border and seasonal workers are excluded from the universe of travellers, what they consume during their stay in the country being visited is included under the item "travel". Both BPM5 and BPM6 thus distinguish, within the world of travel, a physical dimension represented by the flow of travellers and an economic dimension, i.e. what they consume.

The survey on Italy's international tourism also makes it possible to obtain some information needed for the calculation of passenger transport services for the balance of payments. In particular, in this way it is possible to record - on the credit side - the services that resident carriers provide to non-resident passengers for their journeys between Italy and abroad and between (or within) foreign countries (transfers within Italy are to be recorded in the accounts under the item "travel”). On the debit side are recorded transport services provided by non-resident carriers to resident passengers for transfers between Italy and abroad, between two foreign countries and within Italy (those within a foreign country are to be recorded in the accounts under the item "travel"). The foregoing does not apply to cruises; both BPM5 and BPM6 require the related amounts to be assigned to the item "travel", because the tourism component is deemed to outweigh the transport component.

Among the distinctive features of the switch from the fifth edition of the balance-ofpayments manual to the sixth, for the item "travel” it should be noted that the business travel segment must include not only what travellers consume but also acquisitions of goods and services for personal use by cross-border, frontier and other workers who are not resident in the country in which they are employed and whose employer is resident in that country; instead, acquisitions of goods and services by diplomats, consular staff, military personnel, and so forth 
in the territory in which they are posted are to be included under the item "government goods and services” as is now the case for BPM5.

According to BPM6, the following must be excluded from the item "travel" (and included in the item "goods"): goods for resale, the acquisition of valuables (such as art objects and jewellery) and consumer durables, other consumer purchases for own use or to give away that are included in customs data in excess of customs thresholds, except for goods acquired locally and kept in the country being visited (e.g. in a holiday home).

Lastly, BPM6 introduces a series of additional items that divide total expenditure between "goods", "local transport services", “accommodation services", "food and drink" and other "health- and study-related services"; this breakdown is useful for the calculation of the Tourism Satellite Account of the national accounts.

\section{A2. The tourism account of the EU countries}

The euro-area countries use a variety of different observation systems for the compilation of their balance of payments. The differences are reflected in the legislation that regulates the statistical requirements of the European System of Central Banks and the European Commission. A guideline issued by the $\mathrm{ECB}^{40}$ reaffirms the application of the principle of subsidiarity for the input of balance-of-payments data, so that the ECB, although it has the authority to specify and directly manage a harmonized system, delegates the inputting of the data to the individual national central banks, while nonetheless requiring the harmonization of the output of the data (definitions, frequency, promptness and transmission of the data) and a high level of quality.

The tourism balance is also based on observation methods that vary from one euro-area country to another. In these countries the main source of data on outgoing expenditure is a sample survey of resident households, ${ }^{41}$ while sample surveys conducted at the frontier are the most common source of data on incoming expenditure.

Other methods of observation are surveys of accommodation facilities (only for inbound flows), bank settlements and other administrative sources, and statistical estimates. In some countries the tourism account is compiled using several sources.

The choice of method for observing tourism expenditure depends above all on the possibility of measuring the flows of traffic at road border crossings and the budget available. In this sense the application of the Schengen Agreement ${ }^{42}$ has made it more difficult to monitor border traffic, ${ }^{43}$ while administrative sources and surveys conducted at suppliers of tourist services (accommodation facilities or tourist agencies and tour operators) are generally less expensive than extensive sample surveys (either involving households or at border crossings).

40 ECB (2003), Guideline of the European Central Bank of 2 May 2003 on the statistical reporting requirements of the European Central Bank in the field of balance of payments and international investment position statistics, and the international reserves template (ECB/2003/7).

41 The household survey can be used for outbound flows only because there exists a list of residents within a country, while for inbound flows this system is not feasible because there is no list of non-residents who can be contacted to obtain information on travel in the country in question.

42 The Schengen Agreement provides for the progressive elimination of border controls at common frontiers and introduces a free circulation regime for the citizens of the signatory states. All the euro-area countries, except Cyprus and Ireland, have signed the Agreement.

43 As will be seen in Appendix A4, to carry out a sample survey at border crossings, it is necessary to interview travellers who are crossing the border to determine the amount spent; in many cases the impossibility of stopping vehicles at the border leads to the decision not to use a border survey but alternative sources. 
As mentioned, Italy began to conduct its border sample surveys on international tourism in 1996. At that time the only other euro-area country to conduct a similar survey was Ireland. ${ }^{44}$

Subsequently, other countries chose this type of source for inbound flows: France, ${ }^{45}$ Cyprus, Finland, Greece and Malta (the last two for outbound flows as well). Spain carries out two border sample surveys ${ }^{46}$ and uses an econometric model with the data from these surveys and other indicators correlated with tourism expenditure. Austria carries out a sample survey on foreign holiday tourists lodged in accommodation facilities to obtain average daily expenditure, which is then multiplied by the number of persons staying in the accommodation in question; to observe the expenditure of business tourists, excursionists and underground tourism, Austria uses various sources, including mirror data ${ }^{47}$ of other countries. Belgium, Luxembourg, the Netherlands, Slovenia and Slovakia carry out surveys at official forms of accommodation and then supplement the results from other sources to obtain an estimate of expenditure; ${ }^{48}$ Germany still uses bank settlements, supplemented by data on credit cards and mirror data; Portugal supplements bank settlements with travel agency data and Banco de Portugal estimates based on real and price indicators of tourist activity, made using Portuguese Central Statistical Institute data on the flows of travellers.

As regards debits, most euro-area countries use only data from sample surveys conducted at resident households: this is the case of Austria, Belgium, Cyprus, Finland, Germany, Luxembourg, the Netherlands and Slovenia. In addition to the data obtained from households, France uses a monthly panel survey of 500 web users to estimate the expenditure of French business travellers; Ireland uses data coming from sample border surveys, while Portugal uses bank settlements and data coming from travel agencies; Spain uses bank settlements, mirror data and univariate analyses; and Slovakia uses surveys conducted at travel agents and tour operators.

\section{A3. The survey on Italy's international tourism - Objectives}

Among the possible observation techniques available for the compilation of the item "travel”, the Italian Foreign Exchange Office chose to conduct a sample border survey, since the other traditional forms of survey on tourism (conducted at travel agents and accommodation facilities or at households) were able to cover international tourism only in part (inbound for the former and outbound for the latter) and gave rise to a serious problem when trying to combine different sources.

This methodological choice has a cost, however, in excess of what is needed to conduct the other types of survey, primarily because it requires the presence of interviewers at a sample of border crossings during the whole year.

France also uses data from contiguous countries owing to the difficulty of estimating the expenditure of travellers entering France at road border crossings.

46 The EGATUR survey collects data on the expenditure of foreign tourists in Spain; FRONTUR observes the number and some of the characteristics of the tourists.

47 Mirror statistics consist in the bilateral comparison of economic flows between two countries. Since the credits of country $\mathrm{X}$ vis-à-vis country $\mathrm{Y}$ are conceptually equal to the debits of country $\mathrm{Y}$ vis-à-vis country $\mathrm{X}$, a country can measure its tourist inflows using the outflows coming to it from the other countries.

48 For example, every five years the Netherlands conduct a survey on the tourist spending of the customers of accommodation facilities; Slovenia uses a border survey for the expenditure of day-trippers, while Slovakia supplements the data from accommodation facilities with a survey conducted at travel agents and tour operators. 
Moreover, in the design phase it was necessary to resolve the problem of defining the reference population, because promptly updated and sufficiently disaggregated official administrative data on travellers' border crossings were not available. It was therefore necessary to perform qualified counts to estimate the number of travellers making crossings and their country of residence.

After running a pilot survey in the summer of $1995,{ }^{49}$ the survey proper began in January 1996 and involved about 160,000 interviews and 1,700,000 qualified-count operations. Since then the structure of the survey has not been altered although, thanks to the data acquired over the years, it has been possible to reduce the initial number of border crossings in the sample, interviews and qualified counts.

The main objectives of the sample are:

- to obtain better quality statistics for the items "travel" and "passenger transport" of the balance of payments and better meet the needs of international organizations. Although the main reference entity for the survey is the IMF, which defines the criteria for compiling balance-of-payments statistics, the survey was nonetheless also organized to meet the methodological requirements of other international organizations, such as Eurostat, the OECD and the World Tourism Organization (UNWTO)

- to provide further information on the features of the tourism market (characteristics of travellers and of the journey made, type of expenditure, travellers' satisfaction, etc.) of help in better understanding the phenomenon by government bodies, researchers, the tourist industry, students, etc.

\section{A4. The survey on Italy's international tourism - The design of the sample}

The sample survey on Italian international tourism uses a two-stage sample design. The sampling is carried out separately for the different types of border, even though the general sampling principles are the same.

The choice of border crossings to sample is as follows: 82 border crossings are chosen among those ranking highest in terms of traffic (42 road crossings, 5 railway crossings, 24 airports and 11 ports). At the start of the survey the choice was based on Istat data; subsequently reference was made to the results of the earlier surveys. A few border crossings were selected to obtain data on origins and destinations that would otherwise have been scarcely represented.

The border crossings chosen cover a large proportion of the international travellers crossing Italy's borders (Table A.1). In the first year in which the survey was conducted (1996), the road border crossings in the sample covered $90 \%$ of the total number of international travellers at road border crossings; from 1997 onwards the number of road border crossings in the sample was reduced, although minimizing the loss of information by means of cluster analysis techniques, which led to the exclusion of some minor border crossings. ${ }^{50}$ Consequently the cover at road border crossings dropped to $72 \%$.

49 In the months of July, August and September 1995 about 46,000 interviews were carried out and 300,000 qualified-count operations at 50 border crossings.

50 There are hundreds of secondary road border crossings - especially in the provinces of Varese and Como (with Switzerland) and of Gorizia and Trieste (with Slovenia) - that are mainly used for "local” international traffic. They contribute negligible flows of international expenditure. 


\section{Percentage cover of the number of international travellers by type of border crossing}

\begin{tabular}{ccl}
\hline $\begin{array}{c}\text { TYPE OF BORDER } \\
\text { CROSSING }\end{array}$ & $\begin{array}{c}\text { COVER } \\
\text { (\%) }\end{array}$ & SOURCE \\
\hline Road & 72 & Istat (1996) \\
Port & 91 & Istat (1996) \\
Airport & 95 & ENAC (2001) \\
Railway & 98 & Istat (1996) \\
\hline
\end{tabular}

Two types of sampling are carried out at border crossings: qualified counts and interviews.

\section{A5. The survey on Italy's international tourism - Qualified counts}

In the absence of a sampling frame of international travellers crossing Italy's borders, disaggregated by country of residence and serving to define the reference population of the survey for the estimation of the tourism balance of payments, it is necessary to have recourse to qualified counts (hereinafter counts) of travellers in order to estimate the size of the reference population.

To carry out the counts, a two-stage sampling method has been adopted: the first stage consists in time intervals (road border crossings) and origin/destination pairs (other border crossings) to be sampled. From within these first-stage units travellers are extracted at fixed intervals (second-stage units).

The counts are carried out independently at the various types of border crossings and different solutions are adopted according to the different types of information available and the logistics of the various border crossings sample.

For road border crossings, since data are currently not available on crossings by nationality, the observation of the population of travellers is carried out exclusively by means of the continuous monitoring of the flows in transit. The design of the sample is therefore based on the sampling of time, where the month represents the population and the units of time represent the sample units. The units of time are selected in such a way that they are representative of the time zones. For the crossings with higher traffic intensities, an additional stratification variable is the type of day (business day or holiday), on the assumption that the numbers and types of travellers are significantly different in the two levels. The counts are carried out close to the border crossings. The sampling is systematic: the observer fixes a counting rate (e.g. 1 out of 10) for the vehicles to be selected according to the volume of traffic at the border crossing, counts the number of passengers in the vehicle selected and observes the nationality of the vehicle's number plate (on the assumption that this is an approximation of the country of residence of the passengers). The number of passengers - disaggregated by nationality - counted during the shift is expanded to the universe (month) by multiplying it by an expansion coefficient equal to the hours of the day and the hours actually observed, and then multiplying the value obtained by the number of days in the month in question. An adjustment is calculated to take account of travellers who cross the border during the night hours and of the border crossings not in the sample. 


\section{A6. The survey on Italy's international tourism - Interviews}

The interviews are conducted at the border crossings selected in the sampling plan. Travellers are approached by the interviewers, who ask them a set of questions face to face, using a structured questionnaire that the interviewer fills in according to the answers given. The average duration of the interview is 7 minutes for "stay overnight" and 5 minutes for "do not stay overnight" and it is conducted at the end of the international trip (i.e. upon departure from Italy for non-residents and upon arrival in Italy for residents) thus fulfilling two essential requirements for data quality:

- Measuring the amount of expenditure by the interviewee;

- Minimizing any distortion of the information due to faulty recollection. ${ }^{51}$

At some of the motorway border crossings with Schengen countries, ${ }^{52}$ the interviews were conducted with the assistance of members of the police force or border police, which may assist in recording traffic conditions under the provisions of Legislative Decree 285/1992. At border crossings, available personnel stopped random vehicles for checks and then asked the driver to answer the questionnaire with the interviewer. At borders with Schengen countries where no officials were present the interviews were conducted at the point nearest to the frontier ${ }^{53}$ where it would be safe for the interviewers to approach drivers. This distorts the sample somewhat as short-distance travellers tend to stop at service stations less often than others. Interviews conducted in such circumstances are therefore corrected using a coefficient based on data from border crossings where police assistance is used or on data from the time before the Schengen Agreement.

The observed variables are listed in the questionnaire. Briefly, the questionnaire covered the following information:

- Details of the interview: date, duration, border crossing, type and characteristics of the vehicle used.

- Details of the interviewee: gender, age, profession and place of residence (municipality for Italians; country of origin for foreigners).

- Starting point and destination: breakdown by town for the starting point of Italian travellers and by town of destination for foreign tourists; breakdown by country of residence for foreign tourists and by country of destination for Italian travellers.

- Accommodation facilities used.

- Purpose of journey, including reason for holiday.

- Number of travellers, duration of journey and overnight stays, including type of accommodation used.

- Expenditure divided into the following categories of goods and services purchased: transport (international, inside Italy, or inside foreign countries), accommodation (including meals taken in the accommodation facility, at restaurants and cafés, purchases from shops, purchases of other services not included in the foregoing). Expenditure is broken down

51 The problem of recollection in sample surveys has been discussed in numerous publications. See, for example, Sudman and Bradburn (1973).

52 Among the countries that share a border with Italy only Switzerland has not signed the Schengen Agreement and carries out border controls. France, Austria and, more recently, Slovenia have opened up their motorway borders and no longer carry out controls.

53 Interviews were usually conducted at the service station closest to the border crossing. 
according to means of payment used and time when payment was made (pre-paid or at place of stay).

- Opinion of the place where the longest period of the holiday was spent.

\section{A7. Comparing the international tourism survey and Istat's estimates}

There are other sources of information on Italian inbound and outbound tourism besides the Bank of Italy's survey. Istat produces estimates of both based on two major surveys, "Guest arrivals and departures at accommodation facilities" and "Travel and Holidays". The first survey was instituted in the 1950s as a census of registered tourist accommodation and it records the number of people, their place of residence and the number of overnight stays in hotels and other accommodation based on information provided by the facilities. The data are then grouped by town, tourist agency and region before publication by Istat. The multipurpose "Travel and Holidays" sample survey is conducted among some 14,000 Italian households. The aim is to quantify the trips (with overnight stay) made by Italian residents both in Italy and abroad and to gather information on holiday habits and preferences. The sample population consists of households resident in Italy and their members.

The two Istat surveys and the present survey of international tourism therefore overlap in some areas regarding the population observed. Table A.2 sets out the scope of the three main tourism surveys. The surveys overlap in two out of three categories of domestic tourism (the two Istat surveys), in inbound tourism (Bank of Italy survey and Istat's "Guest arrivals and departures at accommodation facilities") and in outbound tourism (Bank of Italy survey and Istat's "Travel and holidays"). The sample population varies according to the type of traveller observed (overnight stays and day trippers), the traveller's place of residence and the type of accommodation used. The survey of tourist supply ("Guest arrivals and departures at accommodation facilities") is unable to record travellers staying in unregistered accommodation (private accommodation) and day trippers. The latter are not recorded in the "Travel and Holidays" survey either as its purpose is to examine trips by Italian households with an overnight stay.

Table A.2

\section{Reference population of the principal tourism surveys in Italy}

\begin{tabular}{|c|c|c|c|}
\hline $\begin{array}{l}\text { RESIDENCE AND TYPE OF } \\
\text { VISITOR/ACCOMMODATION }\end{array}$ & $\begin{array}{l}\text { ITALIANS IN ITALY } \\
\text { (DOMESTIC) }\end{array}$ & $\begin{array}{l}\text { FOREIGNERS IN ITALY } \\
\text { (INBOUND) }\end{array}$ & $\begin{array}{l}\text { ITALIANS ABROAD } \\
\text { (OUTBOUND) }\end{array}$ \\
\hline \multicolumn{4}{|c|}{ OVERNIGHT TRIPPERS } \\
\hline Hotel & $\begin{array}{l}\text { Istat-supply } \\
\text { Istat-demand }\end{array}$ & $\begin{array}{l}\text { Istat-supply } \\
\text { Bank of Italy }\end{array}$ & $\begin{array}{l}\text { Istat-demand } \\
\text { Bank of Italy }\end{array}$ \\
\hline $\begin{array}{l}\text { Other "registered" collective } \\
\text { accommodation }\end{array}$ & $\begin{array}{l}\text { Istat-supply } \\
\text { Istat-demand }\end{array}$ & $\begin{array}{l}\text { Istat-supply } \\
\text { Bank of Italy }\end{array}$ & $\begin{array}{l}\text { Istat-demand } \\
\text { Bank of Italy }\end{array}$ \\
\hline Private accommodation & Istat-demand & Bank of Italy & $\begin{array}{l}\text { Istat-demand } \\
\text { Bank of Italy }\end{array}$ \\
\hline \multicolumn{4}{|c|}{ DAY TRIPPERS } \\
\hline - & - & Bank of Italy & Bank of Italy \\
\hline
\end{tabular}

Istat-supply: Census "Guest arrivals and departures at accommodation facilities"

Istat-demand: Sample survey "Travel and Holidays"

Bank of Italy: Survey of international tourism at Italian border crossings. 
The three surveys on international tourism in part cover the same population, although the results produced may differ as a result of the method, timing and purpose.

The methodological differences between the survey "Guest arrivals and departures at accommodation facilities" (MCE - Movimenti dei clienti negli esercizi ricettivi) and the Bank of Italy's Survey of International Tourism (ITI - Indagine sul turismo internazionale) are considerable (see Alivernini and Santoro, 2010). The first is a census and its unit of observation is accommodation facilities, while the Bank's is a sample survey conducted at border crossings that observes tourist demand. More particularly, the MCE survey records guests registered at accommodation facilities, and therefore people who change location during their trip are recorded the same number of times as the facilities they use. The ITI looks at the principal accommodation used during the trip, while in the MCE survey it is possible to obtain a full breakdown of overnight stays by type of accommodation. The Bank's survey is affected by sampling error, Istat's by the possibility of under-reporting by the respondent facilities.

Differences between the results are nonetheless limited thanks to the constant efforts of both Istat and the Bank of Italy to improve the quality of their data. In the case of the number of overnight stays, the variable that can be directly compared in the two surveys, the difference between the Bank of Italy's ITI survey and Istat's MCE survey regarding estimates for 2012 (the last year of this survey for which definitive data are available) is just -0.1 per cent, while at the end of the 1990s it was more than 40 per cent (Figure A.1).

Figure A.1

Overnight hotel stays of foreign tourists: difference between ITI and MCE

(per cent)

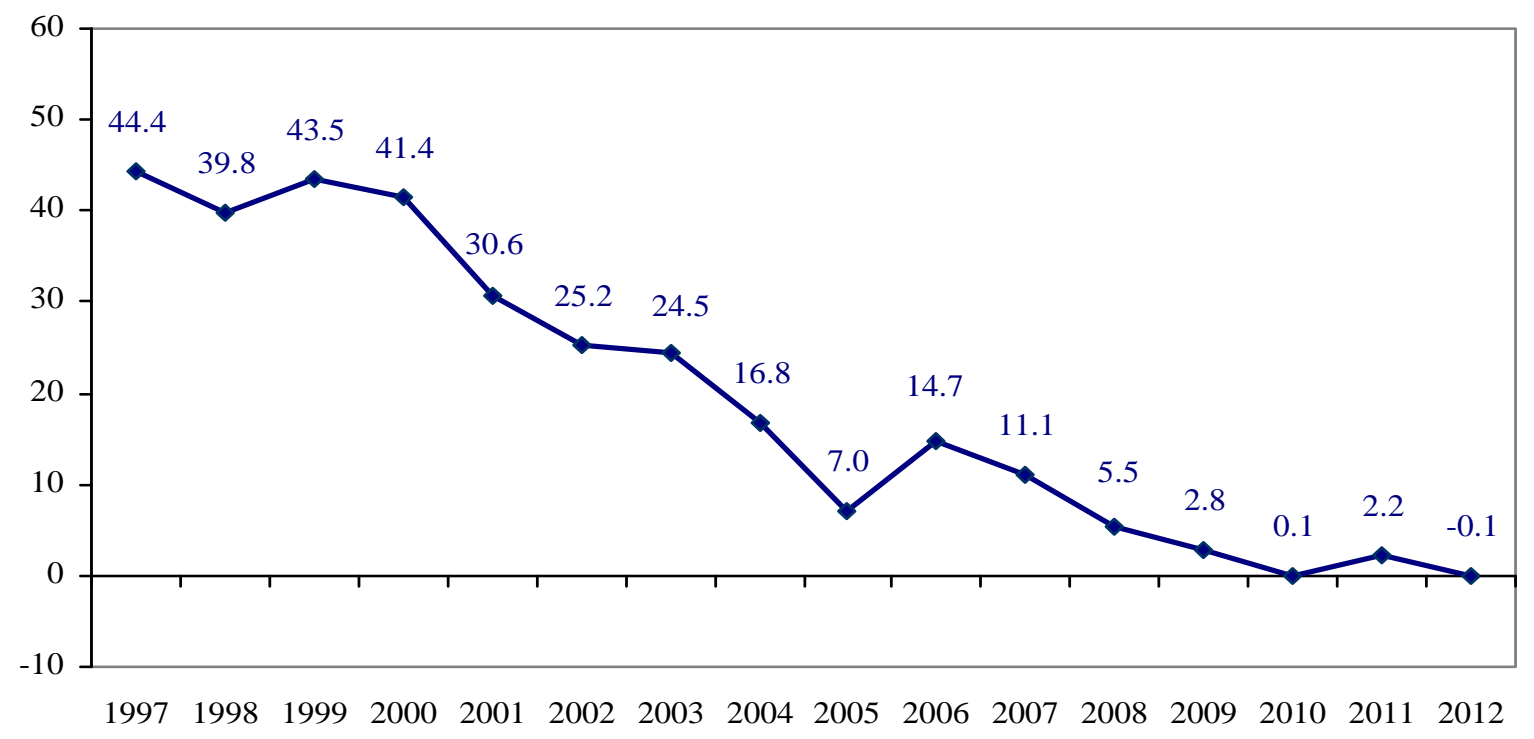

Sources: Bank of Italy and Istat.

A comparison between the Bank of Italy's ITI and the "Travel and Holidays” (T\&H) survey is possible with regard to number of trips and number of overnight stays. Both are sample surveys of tourist demand; the first is conducted at border crossings at the end of the trip and the second is a quarterly survey of the number of trips and overnight stays of Italian households conducted using the CAPI interview technique.

The result of the ITI survey is always significantly greater than that of the T\&H survey, averaging 43.3 per cent for holidays and over 65 per cent for overnight stays (Figure A.2). 
Whereas the differences between the ITI and MCE surveys tend to diminish, this is not so in the case of the ITI and T\&H surveys. The gap is mainly due to recollection problems, which are considerable in the case of the latter survey.

Figure A.2

\section{Italian tourists abroad: difference between ITI and T\&H}

(per cent)

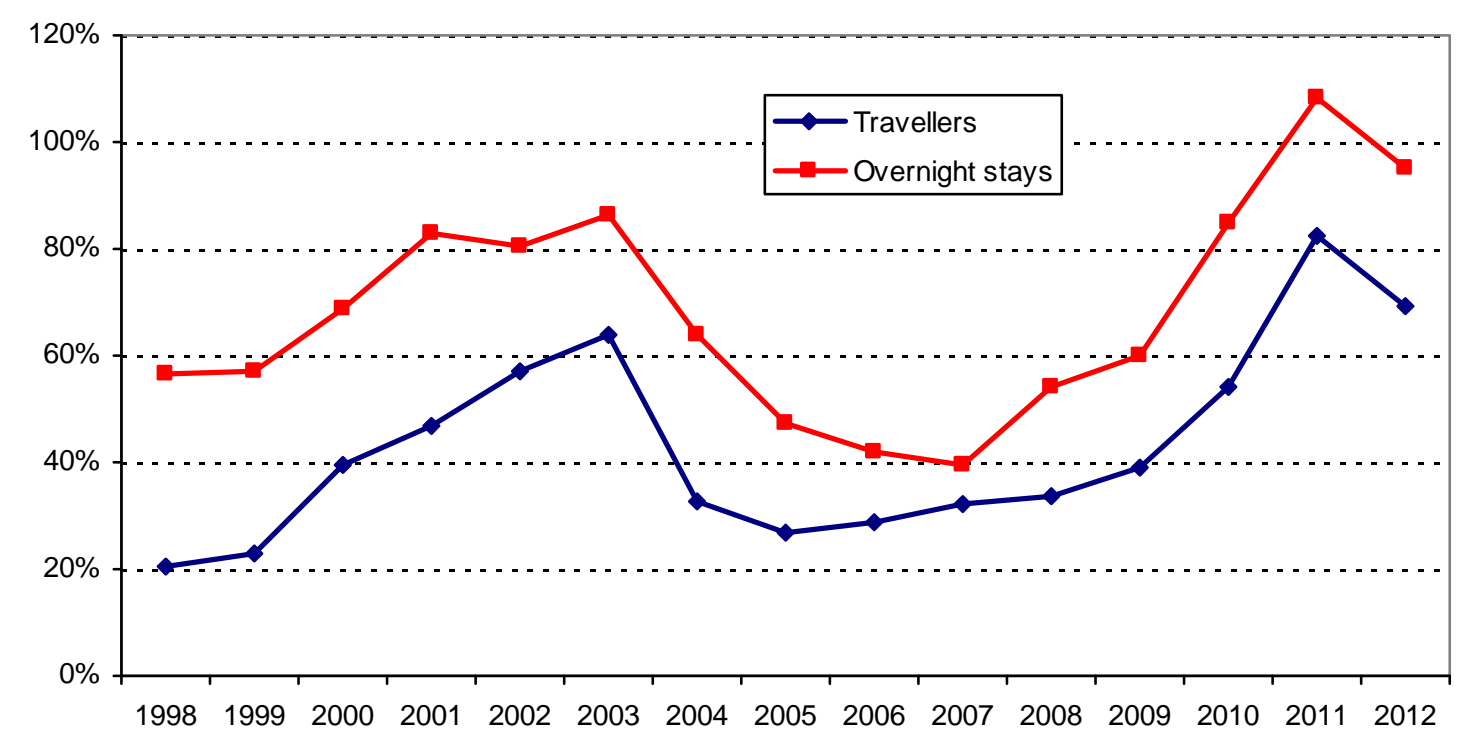

Sources: Bank of Italy and Istat. 


\section{Appendix B - Statistical Tables}

Table B.1

Per capita expenditure per trip, daily per capita expenditure and average length of trip, 1997-2012

(euros and days)

\begin{tabular}{|c|c|c|c|c|c|c|c|c|c|c|c|c|c|c|c|c|}
\hline \multicolumn{17}{|c|}{ Foreign tourists in Italy } \\
\hline & 1997 & 1998 & 1999 & 2000 & 2001 & 2002 & 20032 & 2004 & 2005 & 2006 & 2007 & 2008 & 2009 & 2010 & 2011 & 2012 \\
\hline Per capita expenditure per trip & 439 & 437 & 423 & 461 & 458 & 431 & 426 & 482 & 472 & 450 & 437 & 434 & 398 & 395 & 404 & - 418 \\
\hline Daily per capita expenditure & 86 & 88 & 81 & 84 & 85 & 80 & 81 & 88 & 87 & 87 & 89 & 94 & 92 & 94 & 94 & 98 \\
\hline Average length of trip & 5.1 & 5.0 & 5.2 & 5.5 & 5.4 & 5.4 & 5.3 & 5.5 & 5.4 & 5.2 & 4.9 & 4.6 & 4.3 & 4.2 & 4.3 & 4.3 \\
\hline \multicolumn{17}{|c|}{ Italian tourists abroad } \\
\hline & 19971 & 1998 & 1999 & 20002 & 2001 & 2002 & 20032 & 20042 & 2005 & 2006 & 2007 & 2008 & 2009 & 2010 & 2011 & 2012 \\
\hline Expenditure per trip & 324 & 323 & 323 & 345 & 337 & 359 & 357 & 381 & 391 & 375 & 380 & 365 & 347 & 341 & 358 & 356 \\
\hline Daily per capital expenditure & 68 & 69 & 70 & 71 & 71 & 70 & 68 & 73 & 78 & 81 & 82 & 85 & 82 & 80 & 83 & 80 \\
\hline Average length of trip & 4.8 & 4.7 & 4.6 & 4.9 & 4.8 & 5.1 & 5.2 & 5.2 & 5.0 & 4.6 & 4.7 & 4.3 & 4.2 & 4.3 & 4.3 & 4.4 \\
\hline
\end{tabular}

Table B.2

Day trippers: expenditure and tourists as per cent of total, 1997-2012

(per cent)

\begin{tabular}{llccccccccccccccccc}
\hline & $\mathbf{1 9 9 7}$ & $\mathbf{1 9 9 8}$ & $\mathbf{1 9 9 9}$ & $\mathbf{2 0 0 0}$ & $\mathbf{2 0 0 1}$ & $\mathbf{2 0 0 2}$ & $\mathbf{2 0 0 3}$ & $\mathbf{2 0 0 4}$ & $\mathbf{2 0 0 5}$ & $\mathbf{2 0 0 6}$ & $\mathbf{2 0 0 7}$ & $\mathbf{2 0 0 8}$ & $\mathbf{2 0 0 9}$ & $\mathbf{2 0 1 0}$ & $\mathbf{2 0 1 1}$ & $\mathbf{2 0 1 2}$ \\
\hline \multirow{2}{*}{ Foreigners } & expenditure & 7.8 & 7.8 & 7.8 & 6.8 & 6.8 & 8.0 & 8.4 & 6.0 & 5.6 & 5.3 & 5.8 & 5.8 & 6.2 & 5.9 & 5.3 & 5.3 \\
& tourists & 40.6 & 40.8 & 38.9 & 35.2 & 35.9 & 37.3 & 37.1 & 36.7 & 38.3 & 38.0 & 39.7 & 39.7 & 39.9 & 40.6 & 39.3 & 39.3 \\
\hline \multirow{2}{*}{ Italians } & expenditure & 5.3 & 5.7 & 5.7 & 5.4 & 4.9 & 3.8 & 3.7 & 5.3 & 5.6 & 5.2 & 7.1 & 7.1 & 7.4 & 7.3 & 6.8 & 8.0 \\
& tourists & 59.6 & 60.9 & 60.1 & 57.2 & 56.2 & 51.5 & 49.8 & 49.1 & 50.3 & 50.2 & 53.5 & 53.5 & 52.0 & 52.4 & 51.3 & 52.0 \\
\hline
\end{tabular}


Table B.3

Expenditure of foreign tourists in Italy by country of residence, 1997-2012

(million euros at current prices)

\begin{tabular}{|c|c|c|c|c|c|c|c|c|c|c|c|c|c|c|c|c|c|}
\hline & 1997 & 1998 & 1999 & 2000 & 2001 & 2002 & 2003 & 2004 & 2005 & 2006 & 2007 & 2008 & 2009 & 2010 & 2011 & 2012 & $\begin{array}{c}\text { Average } \\
\text { annual } \\
\% \text { change }\end{array}$ \\
\hline EUROPE & 17,666 & 19,385 & 19,916 & 21,437 & 21,504 & 22,380 & 23,290 & 22,205 & 21,683 & 22,760 & 23,300 & 23,707 & 21,990 & 22,040 & 22,837 & 23,396 & 1.9 \\
\hline$-\mathbf{E U}$ & 14,342 & 16,174 & 16,749 & 18,256 & 18,528 & 19,030 & 19,785 & 19,298 & 18,657 & 19,360 & 19,936 & 20,178 & 18,261 & 18,092 & 18,873 & 19,022 & 1.9 \\
\hline of which: Austria & 1,428 & 1,819 & 2,536 & 2,130 & 2,136 & 2,284 & 2,562 & 1,645 & 1,338 & 1,334 & 1,251 & 1,457 & 1,471 & 1,561 & 1,515 & 1,459 & 0.1 \\
\hline Belgium & 437 & 394 & 399 & 523 & 521 & 608 & 576 & 708 & 646 & 706 & 658 & 748 & 676 & 677 & 780 & 740 & 3.6 \\
\hline Denmark & 131 & 161 & 207 & 229 & 232 & 209 & 259 & 237 & 293 & 292 & 325 & 285 & 281 & 292 & 277 & 358 & 6.9 \\
\hline France & 1,774 & 2,065 & 2,368 & 2,695 & 2,643 & 3,082 & 3,002 & 2,577 & 2,562 & 2,797 & 2,824 & 2,997 & 2,769 & 2,688 & 2,826 & 2,875 & 3.3 \\
\hline Germany & 6,371 & 6,959 & 6,184 & 6,410 & 6,471 & 6,140 & 6,338 & 6,598 & 5,993 & 5,180 & 5,138 & 5,262 & 4,765 & 4,614 & 5,159 & 5,300 & -1.2 \\
\hline Greece & 473 & 497 & 503 & 486 & 543 & 512 & 599 & 232 & 212 & 231 & 211 & 285 & 311 & 291 & 261 & 192 & -5.8 \\
\hline Netherlands & 512 & 615 & 777 & 922 & 1,013 & 1,018 & 1,049 & 1,110 & 968 & 878 & 1,086 & 1,314 & 1,130 & 932 & 1,100 & 1,051 & 4.9 \\
\hline UK & 1,534 & 1,807 & 1,909 & 2,327 & 2,353 & 2,236 & 2,169 & 2,532 & 2,495 & 2,842 & 3,015 & 2,615 & 2,134 & 2,054 & 2,135 & 2,450 & 3.2 \\
\hline Slovenia & 258 & 308 & 291 & 340 & 462 & 620 & 624 & 268 & 198 & 160 & 169 & 237 & 272 & 287 & 246 & 205 & -1.5 \\
\hline Spain & 499 & 686 & 539 & 1,010 & 828 & 857 & 999 & 867 & 1,117 & 1,387 & 1,534 & 1,413 & 1,389 & 1,406 & 1,344 & 1,239 & 6.3 \\
\hline Sweden & 209 & 186 & 191 & 229 & 261 & 205 & 228 & 275 & 256 & 309 & 281 & 352 & 291 & 304 & 414 & 322 & 2.9 \\
\hline -NON-EU & 3,324 & 3,211 & 3,167 & 3,181 & 2,976 & 3,350 & 3,505 & 2,907 & 3,026 & 3,400 & 3,364 & 3,529 & 3,729 & 3,948 & 3,964 & 4,374 & 1.8 \\
\hline of which: Croatia & 520 & 473 & 406 & 401 & 438 & 670 & 571 & 203 & 82 & 142 & 121 & 107 & 202 & 178 & 156 & 172 & -7.1 \\
\hline Russia & 811 & 711 & 544 & 426 & 412 & 229 & 362 & 162 & 258 & 263 & 378 & 567 & 623 & 830 & 925 & 1,191 & 2.6 \\
\hline Switzerland & 1,421 & 1,623 & 1,806 & 1,852 & 1,677 & 2,030 & 2,157 & 2,053 & 2,128 & 2,331 & 2,181 & 2,105 & 2,157 & 2,170 & 2,070 & 2,012 & 2.3 \\
\hline AMERICA & 4,093 & 3,947 & 3,486 & 4,822 & 4,454 & 3,291 & 2,546 & 4,275 & 4,436 & 5,021 & 4,988 & 4,536 & 4,193 & 4,286 & 4,914 & 5,172 & 1.6 \\
\hline of which: United States & 2,939 & 2,927 & 2,666 & 3,425 & 3,387 & 2,594 & 1,957 & 3,219 & 3,287 & 3,840 & 3,655 & 3,050 & 2,929 & 2,983 & 3,345 & 3,603 & 1.4 \\
\hline AFRICA & 403 & 312 & 378 & 514 & 477 & 380 & 223 & 371 & 479 & 468 & 423 & 512 & 374 & 348 & 358 & 306 & -1.8 \\
\hline ASIA & 3,543 & 2,817 & 2,635 & 2,788 & 2,200 & 1,889 & 1,310 & 1,132 & 1,164 & 1,430 & 1,505 & 1,453 & 1,489 & 1,811 & 1,853 & 2,183 & -3.2 \\
\hline of which: China & 135 & 181 & 192 & 217 & 179 & 200 & 139 & 101 & 113 & 226 & 212 & 217 & 161 & 199 & 245 & 316 & 5.8 \\
\hline Japan & 2,470 & 2,042 & 1,773 & 1,719 & 1,343 & 1,202 & 768 & 402 & 378 & 405 & 439 & 403 & 430 & 540 & 514 & 578 & -9.2 \\
\hline OCEANIA & 555 & 345 & 310 & 359 & 342 & 266 & 253 & 682 & 690 & 688 & 905 & 882 & 810 & 772 & 929 & 1,000 & 4.0 \\
\hline TOTAL & 26,260 & 26,806 & 26,724 & 29,920 & $\mathbf{2 8 , 9 7 7}$ & 28,207 & 27,622 & 28,665 & 28,453 & 30,368 & 31,121 & 31,090 & 28,856 & 29,257 & 30,891 & 32,056 & 1.3 \\
\hline
\end{tabular}


Table B.4

Expenditure of Italian tourists abroad by country visited, ${ }^{1}$ 1997- 2012

(million euros at current prices)

\begin{tabular}{|c|c|c|c|c|c|c|c|c|c|c|c|c|c|c|c|c|}
\hline & 1997 & 1998 & 1999 & 2000 & 2001 & 2002 & 2003 & 2004 & 2005 & 2006 & 2007 & 2008 & 2009 & 2010 & 2011 & 2012 \\
\hline EUROPE & 8,030 & 8,784 & 9,170 & 9,968 & 10,180 & 10,951 & 11,447 & 10,837 & 11,643 & 11,923 & 12,348 & 12,966 & 12,626 & 12,887 & 12,921 & 12,846 \\
\hline - EU & 6,304 & 6,773 & 7,426 & 8,069 & 8,283 & 9,010 & 9,422 & 8,967 & 9,768 & 9,782 & 10,275 & 10,566 & 10,267 & 10,508 & 10,380 & 10,155 \\
\hline $\begin{array}{l}\text { of which: } \\
\text { France }\end{array}$ & 1,680 & 1,704 & 1,683 & 1,676 & 1,973 & 2,179 & 2,049 & 2,019 & 2,207 & 2,240 & 2,340 & 2,264 & 2,325 & 2,287 & 2,020 & 2,057 \\
\hline Spain & 756 & 790 & 807 & 1,193 & 1,255 & 1,483 & 1,457 & 991 & 1,215 & 1,415 & 1,611 & 1,535 & 1,331 & 1,574 & 1,799 & 1,594 \\
\hline Germany & 827 & 894 & 1,204 & 1,288 & 1,188 & 1,089 & 1,201 & 1,434 & 1,249 & 1,276 & 1,290 & 1,362 & 1,165 & 1,273 & 1,134 & 1,296 \\
\hline United Kingdom & 884 & 918 & 986 & 884 & 730 & 807 & 837 & 817 & 1,066 & 869 & 928 & 957 & 975 & 901 & 1,036 & 1,221 \\
\hline Austria & 400 & 463 & 596 & 624 & 570 & 670 & 842 & 1,000 & 1,049 & 907 & 790 & 893 & 1,004 & 885 & 780 & 868 \\
\hline Greece & 333 & 459 & 412 & 394 & 534 & 569 & 593 & 614 & 561 & 652 & 820 & 867 & 879 & 977 & 824 & 615 \\
\hline Slovenia & 178 & 157 & 147 & 162 & 195 & 206 & 207 & 223 & 269 & 194 & 201 & 341 & 390 & 432 & 482 & 480 \\
\hline Netherlands & 199 & 214 & 190 & 182 & 177 & 229 & 234 & 233 & 231 & 267 & 244 & 252 & 238 & 289 & 394 & 328 \\
\hline Romania & 67 & 106 & 130 & 251 & 251 & 332 & 426 & 419 & 550 & 498 & 517 & 588 & 420 & 372 & 269 & 194 \\
\hline -NON-UE & 1,725 & 2,011 & 1,744 & 1,899 & 1,898 & 1,941 & 2,025 & 1,870 & 1,875 & 2,141 & 2,072 & 2,399 & 2,359 & 2,379 & 2,541 & 2,691 \\
\hline $\begin{array}{l}\text { of which: } \\
\text { Switzerland }\end{array}$ & 941 & 1,211 & 1,110 & 1,139 & 1,009 & 987 & 1,107 & 1,010 & 905 & 1,089 & 1,108 & 1,248 & 1,172 & 1,244 & 1,239 & 1,341 \\
\hline Russia & 131 & 114 & 95 & 105 & 138 & 188 & 175 & 196 & 192 & 224 & 218 & 238 & 202 & 219 & 254 & 365 \\
\hline Turkey & 188 & 198 & 83 & 111 & 186 & 175 & 132 & 166 & 197 & 173 & 176 & 205 & 231 & 212 & 318 & 254 \\
\hline Croatia & 195 & 222 & 183 & 225 & 318 & 309 & 285 & 150 & 157 & 260 & 147 & 259 & 310 & 251 & 311 & 182 \\
\hline AMERICA & 4,319 & 4,525 & 4,084 & 4,097 & 3,474 & 3,641 & 3,794 & 2,745 & 3,003 & 3,085 & 3,453 & 3,571 & 3,262 & 3,273 & 3,447 & 3,490 \\
\hline $\begin{array}{l}\text { of which: } \\
\text { United States }\end{array}$ & 2,233 & 2,376 & 2,284 & 2,238 & 1,795 & 2,077 & 1,922 & 1,390 & 1,507 & 1,570 & 1,686 & 1,801 & 1,654 & 1,773 & 1,956 & 2,016 \\
\hline Brazil & 383 & 432 & 377 & 432 & 352 & 373 & 381 & 280 & 331 & 408 & 437 & 443 & 501 & 474 & 480 & 444 \\
\hline Mexico & 316 & 317 & 263 & 261 & 282 & 243 & 373 & 236 & 255 & 255 & 269 & 296 & 165 & 187 & 202 & 189 \\
\hline AFRICA & 929 & 960 & 946 & 1,117 & 1,349 & 1,618 & 1,493 & 1,434 & 1,564 & 1,605 & 1,899 & 2,053 & 1,865 & 1,793 & 1,398 & 1,496 \\
\hline $\begin{array}{l}\text { of which: } \\
\text { Egypt }\end{array}$ & 267 & 189 & 239 & 289 & 372 & 535 & 428 & 327 & 398 & 446 & 514 & 672 & 559 & 636 & 352 & 401 \\
\hline Tunisia & 151 & 158 & 127 & 163 & 254 & 338 & 273 & 267 & 326 & 273 & 238 & 305 & 266 & 247 & 184 & 258 \\
\hline Morocco & 133 & 143 & 92 & 135 & 191 & 175 & 199 & 235 & 197 & 280 & 416 & 436 & 265 & 281 & 211 & 181 \\
\hline ASIA & 1,158 & 1,334 & 1,386 & 1,516 & 1,298 & 1,318 & 1,170 & 1,199 & 1,438 & 1,435 & 1,800 & 1,934 & 1,892 & 2,074 & 2,362 & 2,233 \\
\hline $\begin{array}{l}\text { of which: } \\
\text { China }\end{array}$ & 126 & 230 & 199 & 192 & 205 & 220 & 141 & 268 & 381 & 319 & 404 & 405 & 370 & 516 & 585 & 629 \\
\hline Thailand & 140 & 151 & 179 & 157 & 127 & 105 & 105 & 123 & 123 & 139 & 189 & 250 & 238 & 140 & 238 & 257 \\
\hline Dubai & 9 & 52 & 14 & 59 & 72 & 86 & 79 & 65 & 68 & 99 & 199 & 202 & 195 & 207 & 218 & 231 \\
\hline India & 131 & 193 & 156 & 152 & 115 & 96 & 96 & 89 & 112 & 138 & 175 & 203 & 142 & 172 & 253 & 207 \\
\hline Japan & 58 & 55 & 156 & 205 & 151 & 188 & 192 & 137 & 170 & 163 & 130 & 125 & 123 & 182 & 206 & 164 \\
\hline OCEANIA & 169 & 201 & 241 & 298 & 215 & 245 & 291 & 238 & 262 & 284 & 378 & 350 & 311 & 338 & 388 & 409 \\
\hline $\begin{array}{l}\text { of which: } \\
\text { Australia }\end{array}$ & 133 & 156 & 71 & 220 & 149 & 139 & 168 & 168 & 180 & 180 & 246 & 232 & 219 & 238 & 307 & 343 \\
\hline Unclassified & 60 & 38 & 46 & 31 & 34 & 38 & 41 & 61 & 91 & 69 & 75 & 48 & 59 & 50 & 67 & 38 \\
\hline
\end{tabular}

${ }^{1}$ The questionnaire allows for a maximum of 4 different destinations visited. Where an Italian resident traveller has visited more than 4 foreign countries only those entered in the questionnaire are broken down, while the others are entered under "Unclassified", together with the answers of interviewees unable to specify their destination. 
Table B.5

Breakdown of expenditure of foreign tourists in Italy by main purpose of trip, 1997-2012 (million euros at current prices)

\begin{tabular}{|c|c|c|c|c|c|c|c|c|c|c|c|c|c|c|c|c|}
\hline & 1997 & 1998 & 1999 & 2000 & 2001 & 2002 & 2003 & 2004 & 2005 & 2006 & 2007 & 2008 & 2009 & 2010 & 2011 & 2012 \\
\hline Personal reasons & 19,189 & 19,867 & 19,849 & 22,255 & 21,929 & 21,568 & 21,616 & 22,754 & 22,702 & 23,839 & 24,295 & 24,250 & 22,617 & 22,877 & 24,570 & 25,905 \\
\hline Holiday & 14,054 & 14,796 & 14,607 & 16,553 & 16,448 & 16,274 & 15,913 & 17,207 & 16,886 & 17,794 & 18,454 & 17,934 & 16,366 & 16,766 & 18,672 & 19,402 \\
\hline Visiting friends or relations & 1,802 & 1,780 & 1,576 & 1,808 & 1,710 & 1,754 & 2,016 & 2,467 & 2,686 & 2,696 & 2,751 & 3,040 & 3,138 & 3,075 & 2,811 & 3,096 \\
\hline Other personal reasons ${ }^{1}$ & 3,333 & 3,292 & 3,666 & 3,894 & 3,771 & 3,540 & 3,687 & 3,081 & 3,130 & 3,349 & 3,089 & 3,276 & 3,112 & 3,036 & 3,087 & 3,407 \\
\hline Business $^{2}$ & 7,071 & 6,938 & 6,875 & 7,665 & 7,048 & 6,639 & 6,005 & 5,911 & 5,751 & 6,529 & 6,826 & 6,839 & 6,240 & 6,380 & 6,321 & 6,150 \\
\hline Total & 26,260 & 26,806 & 26,724 & 29,920 & $\mathbf{2 8 , 9 7 7}$ & 28,207 & 27,622 & 28,665 & 28,453 & 30,368 & 31,121 & 31,090 & 28,856 & 29,257 & 30,891 & 32,056 \\
\hline
\end{tabular}

Table B.6

Breakdown of expenditure of Italian tourists abroad by main purpose of trip, 1997-2012

(million euros at current prices)

\begin{tabular}{|c|c|c|c|c|c|c|c|c|c|c|c|c|c|c|c|c|}
\hline & 1997 & 1998 & 1999 & 2000 & 2001 & 2002 & 2003 & 2004 & 2005 & 2006 & 2007 & 2008 & 2009 & 2010 & 2011 & 2012 \\
\hline Personal reasons & 8,906 & 9,497 & 9,460 & 9,982 & 9,889 & 10,219 & 10,948 & 10,560 & 11,672 & 11,911 & 12,735 & 13,976 & 13,771 & 14,134 & 14,217 & 13,699 \\
\hline Holiday & 5,986 & 6,440 & 6,329 & 6,974 & 6,995 & 7,389 & 7,938 & 7,131 & 7,853 & 8,063 & 8,562 & 8,862 & 8,751 & 9,140 & 9,157 & 8,030 \\
\hline Visiting friends or relations & 577 & 661 & 663 & 713 & 684 & 850 & 1,006 & 1,391 & 1,663 & 1,615 & 1,807 & 2,139 & 1,879 & 1,812 & 1,667 & 1,736 \\
\hline Other personal reasons ${ }^{1}$ & 2,342 & 2,396 & 2,468 & 2,294 & 2,210 & 1,980 & 2,004 & 2,038 & 2,157 & 2,232 & 2,367 & 2,975 & 3,140 & 3,183 & 3,392 & 3,933 \\
\hline Business $^{2}$ & 5,759 & 6,345 & 6,413 & 7,045 & 6,662 & 7,593 & 7,287 & 5,955 & 6,328 & 6,489 & 7,217 & 6,946 & 6,244 & 6,281 & 6,366 & 6,813 \\
\hline Total & 14,665 & 15,842 & 15,873 & 17,026 & 16,550 & 17,811 & 18,236 & 16,515 & 18,001 & 18,399 & 19,952 & 20,922 & 20,015 & 20,416 & 20,583 & 20,512 \\
\hline $\begin{array}{c}2 \text { Includes season } \\
\text { for the purpose } \\
\text { of the IMF Bala }\end{array}$ & $\begin{array}{l}\text { al wor } \\
\text { of tour } \\
\text { nce of }\end{array}$ & $\begin{array}{l}\text { kers a } \\
\text { ism st } \\
\text { Pavm }\end{array}$ & nd cro & $\begin{array}{l}\text { ss-bor } \\
\text { s but n } \\
\text { tanual }\end{array}$ & $\begin{array}{l}\text { rder ce } \\
\text { who co }\end{array}$ & $\begin{array}{l}\text { ommu } \\
\text { ontribu }\end{array}$ & $\begin{array}{l}\text { ters, } \mathrm{w} \\
\text { ite to } \mathrm{t}\end{array}$ & $\begin{array}{l}\text { who ar } \\
\text { he cal }\end{array}$ & $\begin{array}{l}\text { e not } \\
\text { culatic }\end{array}$ & $\begin{array}{l}\text { includ } \\
\text { on of } t\end{array}$ & $\begin{array}{l}\text { led in } \\
\text { ourist }\end{array}$ & $\begin{array}{l}\text { the de } \\
\text { spend }\end{array}$ & $\begin{array}{l}\text { finitio } \\
\text { ing in }\end{array}$ & $\begin{array}{l}\text { of of } t \\
\text { the } 5 \mathrm{tl}\end{array}$ & $\begin{array}{l}\text { ravell } \\
\text { h editi }\end{array}$ & $\begin{array}{l}\text { ers } \\
\text { ion }\end{array}$ \\
\hline
\end{tabular}

